\title{
Effect of Thermal-Related Fit Clearance between Outer Ring and Pedestal on the Vibration of Full Ceramic Ball Bearing
}

\author{
Huaitao Shi, ${ }^{1,2}$ Xiaotian Bai $\mathbb{D}^{1,2}$ Ke Zhang, $^{2}$ Yuhou Wu $\mathbb{D}^{2},{ }^{2}$ and Zinan Wang $\mathbb{D}^{1}$ \\ ${ }^{1}$ School of Mechanical Engineering, Shenyang Jianzhu University, Shenyang, Liaoning 110168, China \\ ${ }^{2} J o i n t$ International Research Laboratory of Modern Construction Engineering Equipment and Technology, Shenyang, \\ Liaoning 110168, China \\ Correspondence should be addressed to Xiaotian Bai; acetyws@163.com
}

Received 1 June 2019; Accepted 4 September 2019; Published 9 October 2019

Academic Editor: Marcello Vanali

Copyright (C) 2019 Huaitao Shi et al. This is an open access article distributed under the Creative Commons Attribution License, which permits unrestricted use, distribution, and reproduction in any medium, provided the original work is properly cited.

\begin{abstract}
Full ceramic bearing can work under a wide range of temperatures, but the thermal deformation difference between the ceramic outer ring and steel pedestal has a great increase with the rise of temperature and leads to obvious impact and friction. In this paper, the thermal deformation difference is considered and the fit clearance is taken as the boundary condition of the dynamic model. Investigations on the dynamic response of the outer ring are conducted, and the effect of thermal-related fit clearance is analyzed at different working temperatures and rotation speeds through parametric study and experiments. Results show that the vibration of the outer ring grows with the temperature and shows different changes with rotation speed as the temperature changes. The variation of working temperature brings difference in the interactions between the outer ring and the pedestal, and the trends of vibration with rotation speed also change at different temperatures. Impact and friction make great contributions to the interactions between the outer ring and the pedestal and show different changes with temperature. This study puts forward a method for the calculation of bearing vibration at variable temperatures and provides theoretical basis for the application of the full ceramic bearings.
\end{abstract}

\section{Introduction}

The rolling bearing is one of the most common components in mechanical equipment, and the demand for bearing performance also rises at the complex conditions. In many fields such as aerospace and nuclear industry, good thermal shock resistance is essential for bearings as they work at a high temperature and a large temperature range. The full ceramic ball bearings compose of ceramic rings and ceramic balls, and the thermal deformations of the components are smaller than those of traditional steel bearings. Therefore, the full ceramic bearing has a more stable performance at a high temperature and a large temperature range and is widely applied in aerospace and nuclear industry fields. However, the pedestals are mostly made of steel and have obvious deformations at a large temperature range. The different deformations bring about the change of fit clearance between the outer ring and pedestal and lead to the fault of outer ring looseness. As a result, the change of fit clearance with temperature determines the vibration of the full ceramic bearing and needs to be studied in detail.

The vibration of the bearing comes from the interactions between the components and can be derived through the dynamic models of the bearing. Many researchers have focused on the dynamic models of rolling bearing, and the factors affecting the vibration were obtained [1]. Gupta first put forward the dynamic model of rolling bearing, and the contact between cages, roller, and raceways were explained based on dynamic theory [2-5]. Wang et al. carried out several studies on the effect of raceway conformity and shape errors and found that the surface roughness of raceways made great effects on the motion state of balls and lubrication performance $[6,7]$. Li et al. studied the effect of contact angle and load distribution and found that the contact angle and load distributions had significant impact on the contact between the balls and inner ring [8]. Zhang 
et al. presented a model to study the effect of axial preload on an angular contact ball bearing with positive clearance and the influence of rotation speed and external loads were also taken into account. The results indicated that a small preload led to the decrease of the loaded ball number, and a high preload also produced additional loads on balls; both conditions had negative effects on bearing service life [9]. Bizarre et al. derived a complete nonlinear model of an angular contact ball bearing with the effect of elastohydrodynamic lubrication and proposed the equivalent parameters for stiffness and damping [10]. Kerst et al. proposed a semianalytical bearing model addressing flexibility of the bearing outer race structure and found that the effect of flexibility affected the dynamic response of the bearing by changing the shape and stiffness of the bearing [11]. Han focused on the skidding behavior of the rolling bearings and pointed out that the skidding behavior varied periodically and led to the change of slipping frequencies. The radial and axial load had obvious impact on the skidding situations and should be considered carefully in the design of rotating machinery $[12,13]$. Other factors such as lubrication conditions [14-16], cage shape [17, 18], and other structural parameters [19-21] were also investigated and proved to have effects under specific working conditions.

It has been proved by $\mathrm{Chen}$ and $\mathrm{Qu}$ in their work that the fit clearance led to the friction and impact between the outer ring and pedestal and the existence of clearance caused the rotor to be periodically lifted by the unbalanced force [22]. The fit clearance changes with working temperatures, and the contact between outer ring and pedestal was crucial for the bearing performance. However, the working temperature is set as constant in most of the studies, and the thermal effect also needs to be considered in precision equipment. Zhou et al. developed a calculation method for the bearing temperature, and the temperature distribution is used to obtain the thermal deformation of the inner and outer rings [23]. Neisi et al. presented a dynamic and thermal model of a touchdown bearing and calculated the heat generation with surface waviness. The result indicated that the amplitude of the waviness has a great effect on contact forces between balls, rotor, and inner race, thus affecting the temperature rise [24]. Nevertheless, the heat and temperature rise considered merely came from the friction between the bearing components while running. The temperature rise for full ceramic ball bearing is usually 60-70 degrees centigrade, and the difference in the contact between the components is almost negligible as the thermal deformation is small for ceramic materials. On the other hand, the working ambient temperature range can reach 400-500 degrees centigrade, and there is a big difference between the thermal deformation of the outer ring and pedestal. As a result, the fit clearance varies obviously and brings about the problem of a loose outer ring. In previous studies $[25,26]$, the dynamic model of full ceramic bearing has been established, but the thermal deformation in a large temperature range is not included. Therefore, a precised model with the effect of fit clearance change at working conditions of large temperature range is quite essential for the prediction of full ceramic ball bearing dynamic characteristics. In this paper, the thermal deformations of the outer ring and pedestal are obtained through the thermal model and the fit clearances at different temperatures are set as boundary conditions to derive the vibration of full ceramic ball bearing. Then, the dynamic characteristics at different temperatures are obtained, and the effect of thermal deformations on the vibration of full ceramic bearings is analyzed and discussed at last.

\section{Dynamic Model of the Bearing and Pedestal}

2.1. Contact Model of the Bearing. In actual working conditions, the inner ring of the bearing has a tight fit with the shaft and the outer ring is mounted in the pedestal. As the pedestal is connected with the foundation and is of high stiffness, the outer ring is often considered as a rigid body, and the coordinate system of the outer ring is regarded as a reference one. The contact model between the balls and rings is shown in Figure 1.

As shown in Figure 1, the coordinate system $\left\{O_{\mathrm{o}} ; X_{\mathrm{o}}, Y_{\mathrm{o}}\right.$, $\left.Z_{\mathrm{o}}\right\}$ shows the position of the outer ring and $\left\{O_{\mathrm{i}} ; X_{\mathrm{i}}, Y_{\mathrm{i}}, Z_{\mathrm{i}}\right\}$ shows the position of the inner ring. $e$ is the eccentricity of the inner ring, and the cage is not shown here for clarity. $\left\{O_{\mathrm{b} j} ; X_{\mathrm{b} j}, Y_{\mathrm{b} j}, Z_{\mathrm{b} j}\right\}$ shows the position of the $j$ th ball, and the direction of $O_{\mathrm{b} j} Z_{\mathrm{b} j}$ is along the direction of $\mathrm{O}_{\mathrm{o}} \mathrm{O}_{\mathrm{b} j}$. $Q_{\mathrm{i} j}$ is the contact force between the inner ring and the $j$ th ball, and $Q_{\mathrm{o} j}$ is the contact force between the outer ring and the $j$ th ball. $F_{\mathrm{R} \xi \mathrm{ij}}$ and $F_{\mathrm{R} \eta \mathrm{ij}}$ are the friction forces between the $j$ th ball and the inner ring in the planes $X O Z$ and $Y O Z$, respectively, and $F_{\mathrm{R} \xi o j}$ and $F_{\mathrm{R} \eta \mathrm{oj}}$ are the friction forces between the $j$ th ball and the outer ring. $T_{\xi_{i j}}$ is the traction force given by the inner ring, and $F_{\mathrm{a}}$ is the axial preload. $\alpha_{\mathrm{i} j}$ and $\alpha_{\mathrm{o} j}$ are the contact angles between the $j$ th ball and the rings. As has been proved in the previous work [25], the diameter differences between the balls of full ceramic bearing make significant impact on loading conditions of the balls, and the ball can be regarded as in contact with the inner ring when

$$
\overline{\mathrm{O}_{\mathrm{i}} \mathrm{O}_{\mathrm{bj}}} \leq R_{\mathrm{i}}-\left(\frac{r_{\mathrm{i}}-D_{j}}{2}\right) \cos \alpha_{\mathrm{i} j},
$$

where $\overline{O_{\mathrm{i}} O_{\mathrm{b} j}}$ is the projection of the distance of $O_{\mathrm{i}}$ and $O_{\mathrm{b} j}$ in the plane $X_{\mathrm{i}} O_{\mathrm{i}} Z_{\mathrm{i}}$ and $R_{\mathrm{i}}$ is the distance from $O_{\mathrm{i}}$ to the curvature center of the inner raceway. $r_{\mathrm{i}}$ is the radius of inner raceway, and $D_{j}$ is the diameter of the $j$ th ball. $\overline{\mathrm{O}_{\mathrm{i}} \mathrm{O}_{\mathrm{b} j}}$ can be expressed as

$$
\overline{O_{\mathrm{i}} O_{\mathrm{b} j}}=\sqrt{e^{2}+{\overline{\mathrm{O}_{\mathrm{o}} \mathrm{O}_{\mathrm{b} j}}}^{2}-2 e \cdot \overline{\mathrm{O}_{\mathrm{o}} \mathrm{O}_{\mathrm{bj}}} \cdot \cos \left(\phi_{j}-\phi_{\mathrm{e}}\right)},
$$

where $\phi_{j}$ and $\phi_{\mathrm{e}}$ are the azimuth angles of the $j$ th ball and inner ring in $\left\{O_{\mathrm{o}} ; Y_{\mathrm{o}}, Z_{\mathrm{o}}\right\}$, and the distance $\overline{O_{\mathrm{o}} \mathrm{O}_{\mathrm{b} j}}$ can be expressed as

$$
\overline{O_{\mathrm{o}} O_{\mathrm{b} j}}=R_{\mathrm{o}}+\left(\frac{r_{\mathrm{o}}-D_{j}}{2}\right) \cos \alpha_{\mathrm{o} j},
$$

where $R_{\mathrm{o}}$ is the distance from $O_{\mathrm{o}}$ to the curvature center of outer raceway and $r_{\mathrm{o}}$ is the radius of outer raceway.

\subsection{Contact Model between the Outer Ring and Pedestal.} It can be inferred from equations (1)-(3) that the position of the loaded balls is related with the ball diameter and the 


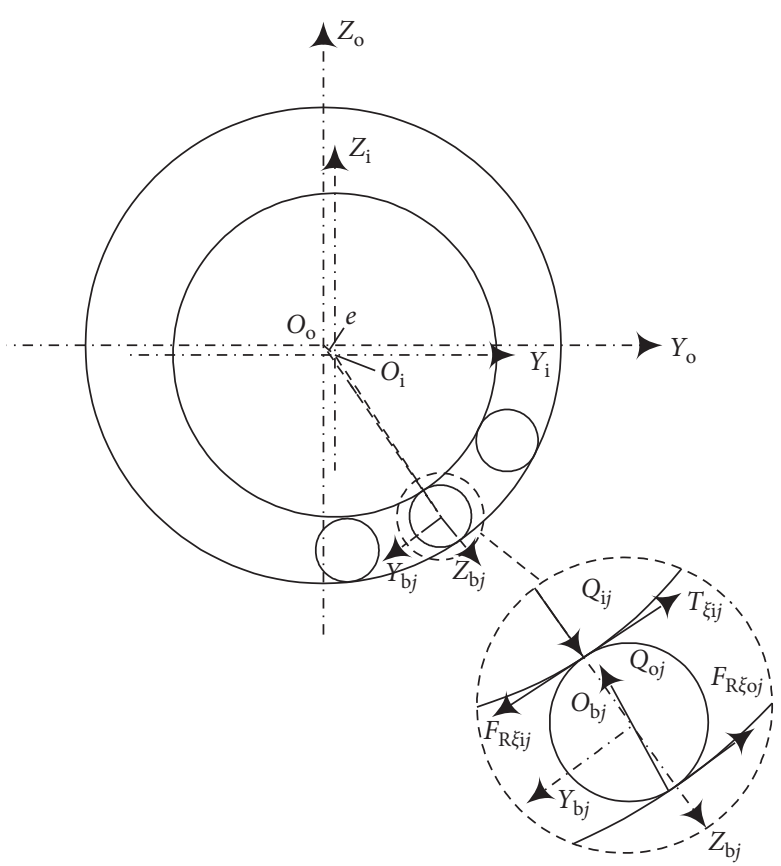

(a)

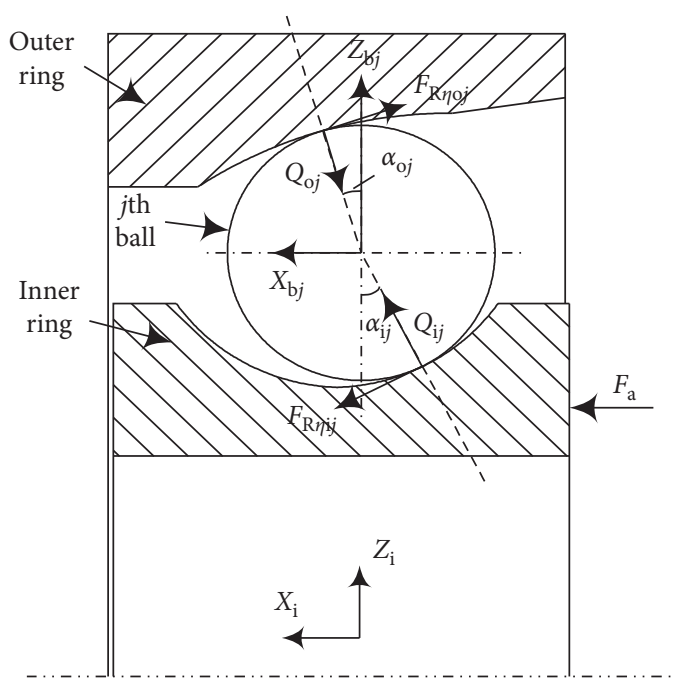

(b)

FIgURE 1: Contact model between balls and rings in the (a) YOZ plane and (b) XOZ plane.

position of the inner ring relative to the outer ring. When the temperature is fixed and the thermal deformation of the pedestal can be ignored, the outer ring can be regarded as a rigid body. However, when the temperature has a large range, the fit clearance between the outer ring and pedestal tends to be influential, and the contact model between the outer ring and pedestal with the effect of fit clearance is shown in Figure 2.

In Figure 2, the coordinate system $\{O ; Y, Z\}$ shows the position of the pedestal and $\dot{y}_{0}$ and $\dot{z}_{\mathrm{o}}$ are the velocities along corresponding directions. The dashed circle shows the inner boundary of the pedestal before deformation, and the dotdashed circle has the same diameter with the outer boundary of the outer ring. The fit clearance between the outer ring and pedestal is $\delta$ with a temperature range of $\Delta T$. Assume that the inner boundary of the pedestal has equal deformations at all directions and the boundaries before and after deformation are concentric circles. As a result, the coordinate system $\{O ; Y, Z\}$ can be considered as a reference, and the outer ring moves within the boundary after deformation. $e_{\mathrm{o}}$ is the eccentricity of the outer ring relative to the pedestal with the azimuth angle of $\phi_{\mathrm{o}}$ and can be expressed as

$$
\begin{aligned}
& e_{\mathrm{o}}=\sqrt{y_{\mathrm{o}}^{2}+z_{\mathrm{o}}^{2}}, \\
& \left\{\begin{array}{l}
\sin \phi_{\mathrm{o}}=\frac{z_{\mathrm{o}}}{e_{\mathrm{o}}}, \\
\cos \phi_{\mathrm{o}}=\frac{y_{\mathrm{o}}}{e_{\mathrm{o}}} .
\end{array}\right.
\end{aligned}
$$

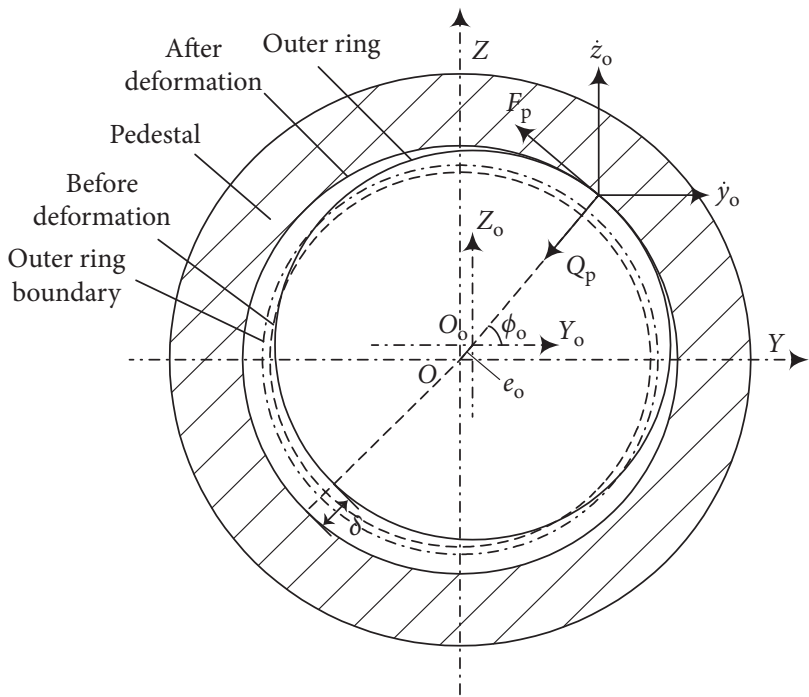

Figure 2: Contact model between the outer ring and pedestal.

When $e_{\mathrm{o}}$ meets that

$$
e_{\mathrm{o}} \geq \frac{\delta}{2}
$$

The outer ring is in contact with the pedestal, as shown in Figure 2. $Q_{p}$ shows the contact force between the outer ring and pedestal, and $F_{\mathrm{p}}$ is the friction force and can be expressed as 


$$
\left\{\begin{array}{l}
Q_{\mathrm{p}}=k_{\mathrm{p}} \cdot\left(e_{\mathrm{o}}-\frac{\delta}{2}\right) \\
F_{\mathrm{p}}=f \cdot Q_{\mathrm{p}} \cdot \frac{\dot{y}_{\mathrm{o}} \sin \phi_{\mathrm{o}}-\dot{z}_{\mathrm{o}} \cos \phi_{\mathrm{o}}}{\left|\dot{y}_{\mathrm{o}} \sin \phi_{\mathrm{o}}-\dot{z}_{\mathrm{o}} \cos \phi_{\mathrm{o}}\right|}
\end{array}\right.
$$

where $k_{\mathrm{p}}$ is the stiffness of the pedestal and $f$ is the friction coefficient between the outer ring and pedestal. $\left(\dot{y}_{\mathrm{o}} \sin \phi_{\mathrm{o}}-\dot{z}_{\mathrm{o}} \cos \phi_{\mathrm{o}}\right)$ shows the velocity along the tangential direction. When $\dot{y}_{\mathrm{o}} \sin \phi_{\mathrm{o}}-\dot{z}_{\mathrm{o}} \cos \phi_{\mathrm{o}}>0$, the outer ring has a tendency of clockwise rotation and the direction of $F_{\mathrm{p}}$ is the same as shown in Figure 2, and when $\dot{y}_{\mathrm{o}} \sin \phi_{\mathrm{o}}-\dot{z}_{\mathrm{o}} \cos \phi_{\mathrm{o}}<0$, the direction of $F_{\mathrm{p}}$ is opposite to that in Figure 2. When $e_{\mathrm{o}}<\delta / 2$, the outer ring is not in contact with the pedestal and $Q_{\mathrm{p}}=F_{\mathrm{p}}=0$. Assume that the deformation only makes impact on the radial dimension of the fit clearance and the axial interaction is not affected. Then, the dynamic differential equations of the outer ring can be expressed as

$$
\begin{aligned}
& \sum_{j=1}^{M}\left(Q_{\mathrm{o} j} \sin \alpha_{\mathrm{o} j}+F_{\mathrm{R} \eta j j} \cos \alpha_{\mathrm{o} j}\right)=m_{\mathrm{o}} \ddot{x}_{\mathrm{o}}, \\
& \sum_{j=1}^{M}\left[\left(Q_{\mathrm{o} j} \cos \alpha_{\mathrm{o} j}-F_{\mathrm{R} \eta j} \sin \alpha_{\mathrm{o} j}\right) \cos \phi_{j}-F_{\mathrm{R} \xi \xi j} \sin \phi_{j}\right] \\
& \quad-Q_{\mathrm{p}} \cos \phi_{\mathrm{o}}-F_{\mathrm{p}} \sin \phi_{\mathrm{o}}=m_{\mathrm{o}} \ddot{y}_{\mathrm{o}}, \\
& \sum_{j=1}^{M}\left[\left(F_{\mathrm{R} \eta \eta j} \sin \alpha_{\mathrm{o} j}-Q_{\mathrm{o} j} \cos \alpha_{\mathrm{o} j}\right) \sin \phi_{j}-F_{\mathrm{R} \xi \xi j} \cos \phi_{j}\right] \\
& \quad-Q_{\mathrm{p}} \sin \phi_{\mathrm{o}}+F_{\mathrm{p}} \cos \phi_{\mathrm{o}}-m_{\mathrm{o}} \mathrm{g}=m_{\mathrm{o}} \ddot{z}_{\mathrm{o}},
\end{aligned}
$$

where $M$ is the number of balls. $m_{\mathrm{o}}$ is the mass of the outer ring, and $\ddot{x}_{0}, \ddot{y}_{0}$, and $\ddot{z}_{\mathrm{o}}$ are the accelerations along $O_{\mathrm{o}} X_{\mathrm{o}}$, $O_{\mathrm{o}} Y_{\mathrm{o}}$, and $O_{\mathrm{o}} Z_{\mathrm{o}}$, respectively.

\subsection{Thermal Deformation of the Pedestal and Outer Ring.} The pedestal can be regarded as a cylindrical body with a hole, as shown in Figure 3. The dashed lines show the boundaries before deformation, and the solid lines show the boundaries after deformation. $D_{0}$ and $D_{1}$ show the outer diameters of the pedestal before and after deformation, and $d_{0}$ and $d_{1}$ show the inner diameters of the pedestal before and after deformation. $L_{0}$ and $L_{1}$ show the length of pedestal before and after deformation. The deformation contains the gravity-induced deformation and thermal-induced deformation and can be expressed as

$$
L_{1}=L_{0}+L_{0} \alpha_{\mathrm{p}} \Delta T-\frac{\rho \mathrm{g} L_{0}^{2}}{2 E_{0}} \alpha_{E} \Delta T
$$

where $\alpha_{\mathrm{p}}$ is the thermal deformation coefficient of the pedestal material, $\Delta T$ is the temperature range, $\rho$ is the material density of the pedestal, and $g$ is the gravitational acceleration, $E_{0}$ is the elastic modulus at the initial temperature $T_{0}, \alpha_{\mathrm{E}}$ is the temperature coefficient of elastic

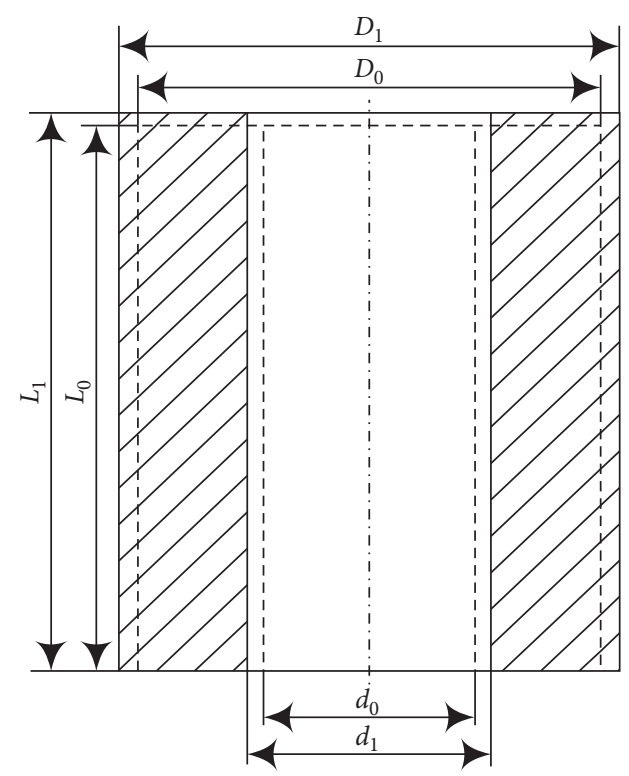

Figure 3: Deformation of the pedestal.

modulus, and the elastic modulus at a given temperature can be expressed as

$$
E(T)=E_{0}\left(1+\alpha_{\mathrm{E}} \cdot \Delta T\right)
$$

where $T=T_{0}+\Delta T$ shows the temperature. The outer boundary of the pedestal is supposed to have a free deformation, that is,

$$
D_{1}=D_{0}\left(1+\alpha_{\mathrm{p}} \Delta T\right) .
$$

When the temperature changes, the whole pedestal has a deformation, leading to the change of volume from $V_{0}$ to $V_{1}$, where $V_{0}$ is the volume before deformation and $V_{1}$ is the volume after deformation and can be expressed as

$$
\left\{\begin{array}{l}
V_{0}=\frac{\pi\left(D_{0}^{2}-d_{0}^{2}\right)}{4} \cdot L_{0} \\
V_{1}=\frac{\pi\left(D_{1}^{2}-d_{1}^{2}\right)}{4} \cdot L_{1} .
\end{array}\right.
$$

For steel materials, there is

$$
\frac{V_{1}-V_{0}}{V_{0}}=3 \alpha_{\mathrm{p}} \Delta T
$$

So it can be derived from equations (14) and (15) that

$$
\left(D_{1}^{2}-d_{1}^{2}\right) L_{1}=\left(D_{0}^{2}-d_{0}^{2}\right) \cdot L_{0}\left(1+3 \alpha_{\mathrm{p}} \Delta T\right) .
$$

Then, $d_{1}$ can be obtained through

$d_{1}=\sqrt{D_{0}^{2}\left(1+\alpha_{\mathrm{p}} \Delta T\right)^{2}-\frac{\left(D_{0}^{2}-d_{0}^{2}\right) \cdot L_{0}\left(1+3 \alpha_{\mathrm{p}} \Delta T\right)}{L_{0}\left(1+\alpha_{\mathrm{p}} \Delta T\right)-\left(\rho g L_{0}^{2} / 2 E_{0}\right) \cdot \alpha_{\mathrm{E}} \Delta T}}$.

The result $d_{1}$ is the diameter of the boundary after deformation in Figure 2, and the deformation of the pedestal can be described as 


$$
\delta_{\mathrm{p}}=d_{1}-d_{0} .
$$

For the outer ring, the deformation can be expressed as

$$
\delta_{\mathrm{o}}(T)=\alpha_{0} \Delta T,
$$

where $\delta_{\mathrm{o}}$ is the deformation of the outer ring at temperature $T$ and $\alpha_{\mathrm{o}}$ is the thermal deformation coefficient of the outer ring. Then, the fit clearance $\delta$ can be expressed as

$$
\delta(T)=\delta_{0}+\delta_{\mathrm{p}}-\delta_{\mathrm{o}},
$$

where $\delta_{0}$ is the initial fit clearance between the outer ring and pedestal at $T_{0}$. The interactions between the balls, the cage, and the inner ring can be obtained in [25], and the contact between the outer ring and the pedestal can be obtained through equations (1)-(10). The fit clearance between the outer ring and the pedestal makes impact on the vibration of the outer ring and leads to the change of interactions of the bearing components. For the detailed derivation of the interactions between the components of the bearing, please refer to the previous work in reference [25].

\section{Numerical Simulation}

The type of the selected ceramic bearing is $7009 \mathrm{C}$ in the analysis, and the major geometric parameters are listed in Table 1.

Assume that the mass centroids of the components match with the shape centers and the bearing works with perfect lubrication. The effects of the shape errors and surface roughness are neglected. The size of the pedestal is shown in Table 2.

The thermal deformation coefficient of the pedestal is $1.25 \times 10^{-5} \mathrm{~K}^{-1}$, and the thermal deformation coefficient of the outer ring is $2.8 \times 10^{-6} \mathrm{~K}^{-1}$. For the full ceramic bearings applied in extreme conditions in aviation engines, the working temperature can reach over $650 \mathrm{~K}$. As a result, the temperature range in the analysis is set from $100 \mathrm{~K}$ to $600 \mathrm{~K}$. The initial temperature $T_{0}$ is set as $100 \mathrm{~K}$, and the temperature coefficient of elastic modulus of the pedestal is $-0.0002 \mathrm{~K}^{-1}$. The density of the pedestal is $7850 \mathrm{~kg} / \mathrm{m}^{3}$, and $E_{0}$ is $2.16 \times 10^{11} \mathrm{~Pa}$. The initial fit clearance is $0.003 \mathrm{~mm}$, and the friction coefficient between the outer ring and pedestal is 0.2 . The change of fit clearance with the temperature is shown in Figure 4.

In Figure 4, the lines with rectangles and circles show the deformations of the pedestal and outer ring and the lines with triangles show the change of the fit clearance. It can be seen from Figure 4 that the thermal deformation of the outer ring is much smaller than that of the pedestal and the fit clearance has an increase of $0.38 \mathrm{~mm}$ when the temperature comes to $600 \mathrm{~K}$. Assuming that the pedestal is fixed, the radial vibration of the outer ring is studied. The axial preload of the bearing is $1000 \mathrm{~N}$, and the radial load applied on the inner ring is $100 \mathrm{~N}$. The responses of the outer ring can be obtained through equations (8)-(10), and the thermal-related fit clearance derived from equations (11)-(20) can be substituted as boundary conditions. The velocity of the outer ring can be used as the indicator and is expressed as
TABle 1: Major geometric parameters of 7009C.

\begin{tabular}{lc}
\hline Item & Value \\
\hline Bearing outside diameter $(\mathrm{mm})$ & 75 \\
Initial contact angle (degree) & 15 \\
Bearing width (mm) & 16 \\
Cage bore diameter (mm) & 62.1 \\
Cage thickness (mm) & 1.45 \\
Outer ring maximum thickness (mm) & 4.55 \\
Cage width (mm) & 14.75 \\
Ball diameter (mm) & 9.5 \\
Number of balls & 17 \\
Inner ring outside diameter $(\mathrm{mm})$ & 54.2 \\
Inner ring bore diameter $(\mathrm{mm})$ & 45 \\
\hline
\end{tabular}

TABle 2: Size of the pedestal.

\begin{tabular}{lcc}
\hline$D_{0}(\mathrm{~mm})$ & $d_{0}(\mathrm{~mm})$ & $L_{0}(\mathrm{~mm})$ \\
\hline 170 & 75 & 50 \\
\hline
\end{tabular}

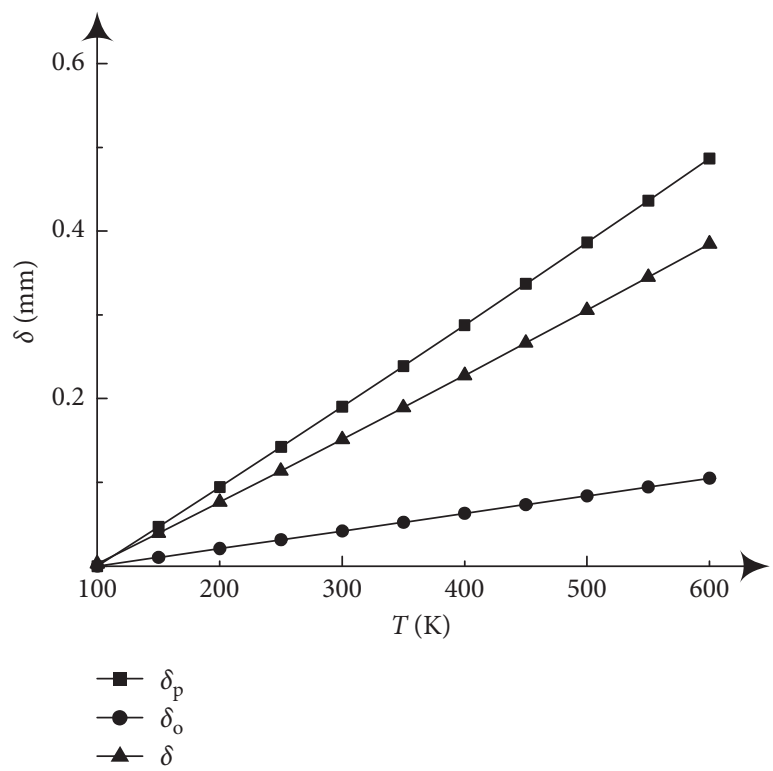

FIgURE 4: Change of fit clearance with temperature.

$$
v=\sqrt{\dot{y}_{\mathrm{o}}^{2}+\dot{z}_{\mathrm{o}}^{2}} .
$$

And the point at the 12 o'clock direction is set as the reference point for the calculation of the outer ring vibration, as shown in Figure 5.

The rotation speed varies from $9000 \mathrm{rpm}$ to $36000 \mathrm{rpm}$ with the calculation step set as $3000 \mathrm{rpm}$, and the vibration results at $T=100 \mathrm{~K}$ and $T=600 \mathrm{~K}$ are shown in Figure 6 .

As indicated in Figure 6, the vibration results at $T=600 \mathrm{~K}$ have significant changes at different rotation speeds and the peak values are related with critical speeds. The results at $T=100 \mathrm{~K}$ vary little with rotation speeds, and the peak values are different from the results of $T=600 \mathrm{~K}$. The fit clearance between the outer ring and pedestal increases with the temperature and the amplitudes of the 


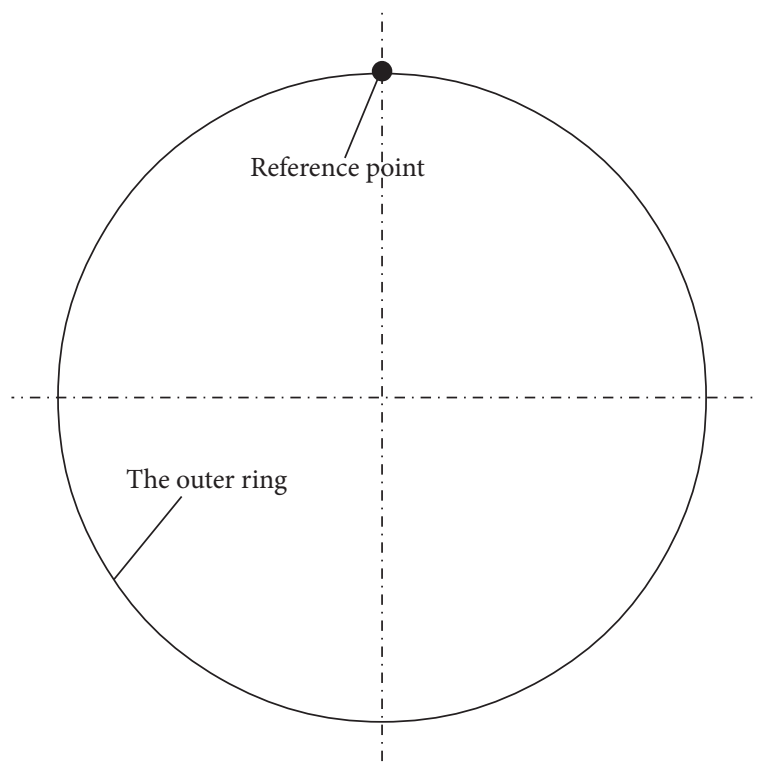

FIGURE 5: Reference point for the calculation of the outer ring vibration.

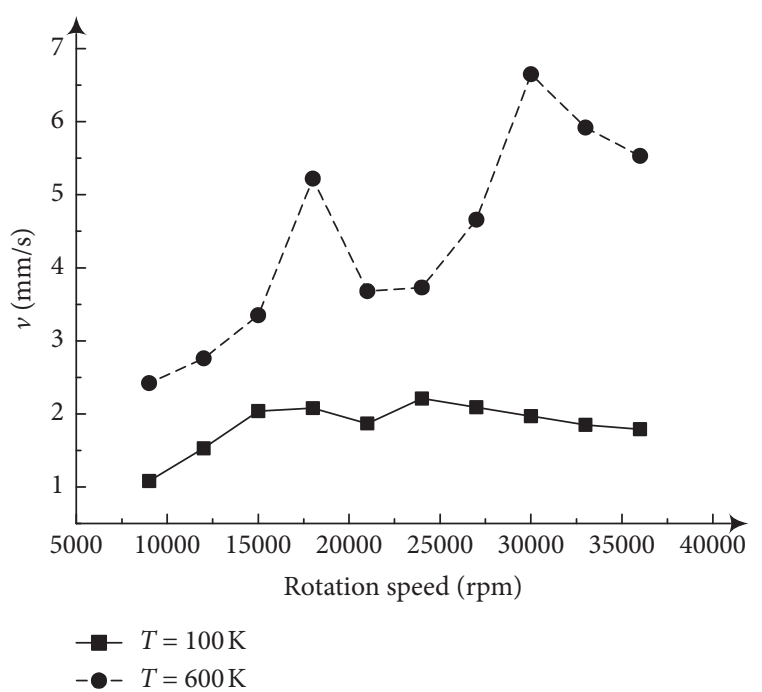

Figure 6: Vibration results at different temperatures.

vibration also rises. The increase of the fit clearance provides larger space for the vibration of outer ring; however, the outer ring does not move in the whole fit clearance. At the rotation speeds when the vibration is not so severe, the motion of the outer ring does not cover the whole inner boundary of the pedestal and the impact between the outer ring and pedestal varies little. At the critical speeds when violent vibration happens, the fit clearance is fully utilized by the outer ring to bring about continuous impact on the pedestal. As a result, the gap between the vibration results is obvious at critical speeds, but small at other rotation speeds. When the rotation speed continues to increase after the critical speeds, the change of motion areas decreases and the vibration results tend to be stable. It can be seen through the comparison that the vibration situations vary a lot at different temperatures and the variation comes from the change of fit clearance. The results need to be verified through experiments, and the impact of temperature needs to be further investigated.

\section{Experimental Investigation}

An experiment is conducted on the full ceramic ball bearingceramic spindle test rig, and the devices of the test rig are shown in Figure 7.

Figure 7(d) shows the assembled status of the test rig during the experiment, and the ceramic spindle applied in the experiment is shown in Figure 7(a). The full ceramic bearings are placed at both the ends, and the oil-air lubrication strategy is carried out through the oil lubrication device and the air compressor shown in Figures 7(g) and 7(h), respectively. The rotation speed can be adjusted manually through the controller, as shown in Figure $7(\mathrm{c})$. The vibration signal is measured by the sensors shown in Figure $7(f)$, and the data are collected by the collector shown in Figure 7(b).

In the experiment, a temperature sensor is embedded in the spindle near the outer ring to get the working temperature of the full ceramic bearing. The working temperature is first lowered by the liquid nitrogen to about $90 \mathrm{~K}$, and then, the refrigeration process is stopped. Then, the ceramic spindle starts to work and the temperature gradually rises. The rotation speed is set as $24000 \mathrm{rpm}$ during the test, and the ambient temperature is about $300 \mathrm{~K}$. The temperature tends to be stable at about $340 \mathrm{~K}$ after 20 minutes, and the vibrations at $100 \mathrm{~K}, 200 \mathrm{~K}$, and $300 \mathrm{~K}$ are selected for comparison. The sampling rate is set as $4000 \mathrm{~Hz}$, and the velocities in the vertical and horizontal directions can be collected through the measurement. The measuring point is also set at 12 o'clock direction in consistent with the reference point in calculation for comparison, as shown in Figure 7(d). The experimental result is calculated through equation (21), and the calculation and experimental results are shown in Figure 8.

In Figure 8, the dashed lines show the experimental results and the solid lines show the calculation results. The calculation results match well with the experimental results, and the peaks are at around $400 \mathrm{~Hz}, 800 \mathrm{~Hz}$, and $1200 \mathrm{~Hz}$, which are related with the rotation speed. It is indicated that the temperature makes impact on the vibration of the outer ring as the amplitudes at the peak frequencies increase when the temperature rises from $100 \mathrm{~K}$ to $300 \mathrm{~K}$. According to equation (20), the fit clearance turns from $0.003 \mathrm{~mm}$ at $100 \mathrm{~K}$ to $0.1515 \mathrm{~mm}$ at $300 \mathrm{~K}$. It can be inferred that as the working temperature rises, the enlargement of the fit clearance leads to more complicated interactions between the outer ring and the pedestal, and more detailed studies on the vibration of the outer ring need to be further carried out.

\section{Analysis on the Vibration of the Outer Ring with Different Condition Parameters}

5.1. Impact of the Temperature on the Vibration of the Outer Ring. In order to get more detailed information about the dynamic characteristics of the full ceramic bearing, the single 


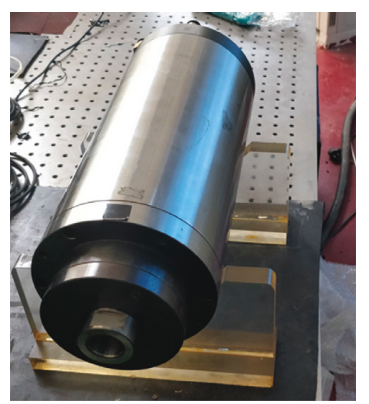

(a)

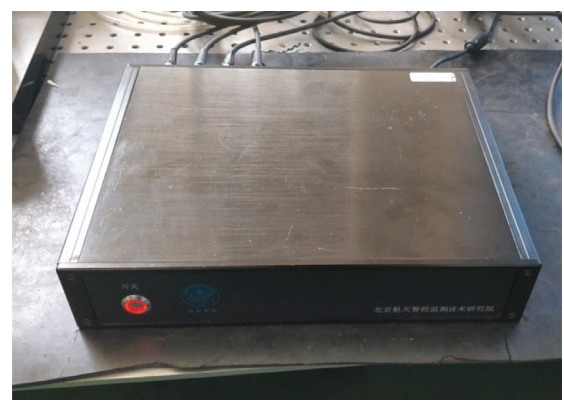

(b)

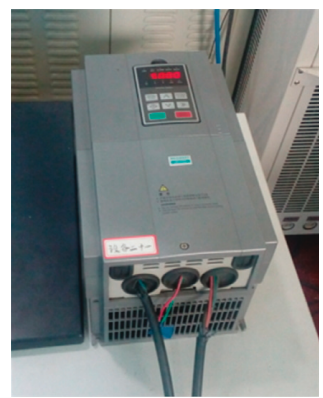

(c)

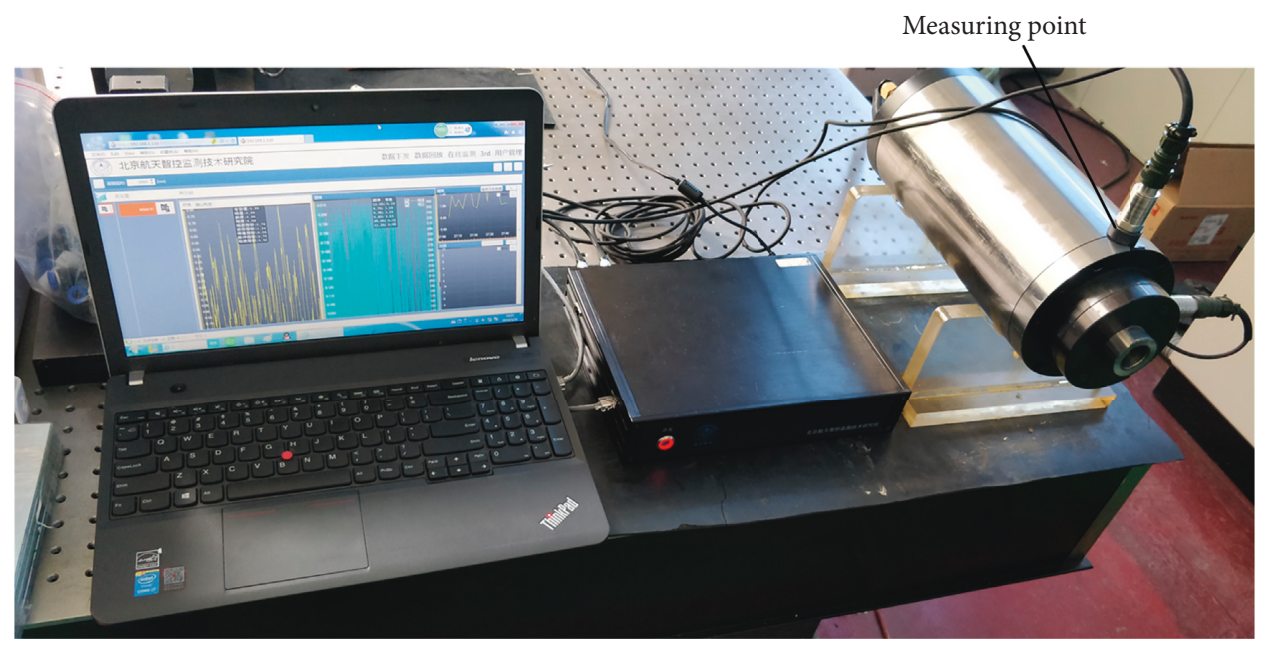

(d)

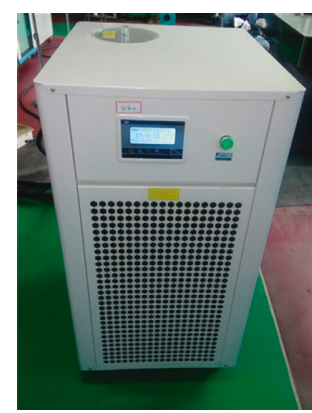

(e)

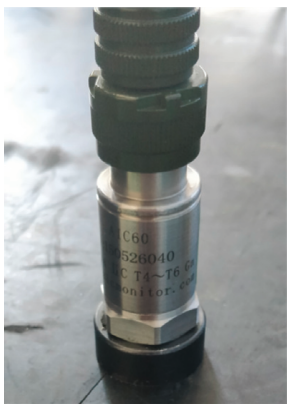

(f)

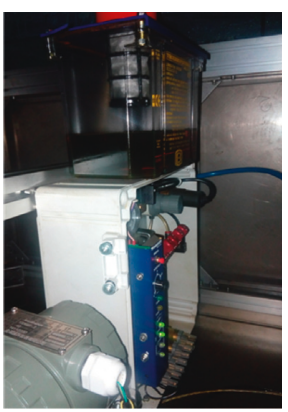

(g)

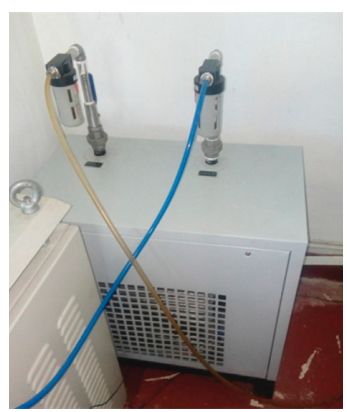

(h)

Figure 7: Experimental devices: (a) ceramic spindle; (b) data collector; (c) controller; (d) test rig; (e) water cooling system; (f) vibration sensor; (g) oil lubrication; (h) air compressor.

factor analysis is conducted to analyze the vibration of the outer ring. The change of the fit clearance between the outer ring and pedestal comes from the thermal deformation difference and is closely related with the temperature. Here, the rotation speed is fixed at $18000 \mathrm{rpm}$, the initial temperature is $100 \mathrm{~K}$, and the initial fit clearance is $0.003 \mathrm{~mm}$. The axial preload is $1000 \mathrm{~N}$, and the radial load is $100 \mathrm{~N}$. The other parameters are the same as the above study. The temperatures of $100 \mathrm{~K}, 200 \mathrm{~K}, 300 \mathrm{~K}, 400 \mathrm{~K}, 500 \mathrm{~K}$, and $600 \mathrm{~K}$ are calculated, and the results are analyzed in the frequency domain. The frequency interval is set from 0 to $2000 \mathrm{~Hz}$, as shown in Figure 9.
As shown in Figures 9(a)-9(f), the main frequency components of the outer ring vibration are related with the rotation speed. The rotation speed is set as $18000 \mathrm{rpm}$, and the corresponding rotation frequency is $f_{\mathrm{r}}=300 \mathrm{~Hz}$. The peak frequencies obtained in the results are $f_{\mathrm{r}}, 2 f_{\mathrm{r}}, 3 f_{\mathrm{r}}, 4 f_{\mathrm{r}}, 5 f_{\mathrm{r}}$, and $6 f_{\mathrm{r}} . f_{\mathrm{r}}$ and $2 f_{\mathrm{r}}$ are the main components as the amplitudes are larger, and the change of the amplitudes of $f_{\mathrm{r}}$ and $2 f_{\mathrm{r}}$ are more obvious with the increase of temperature. The characteristic frequencies remain unchanged, but the amplitudes vary greatly. The changes of amplitudes of the main frequency components with temperatures are shown in Figure 10. 


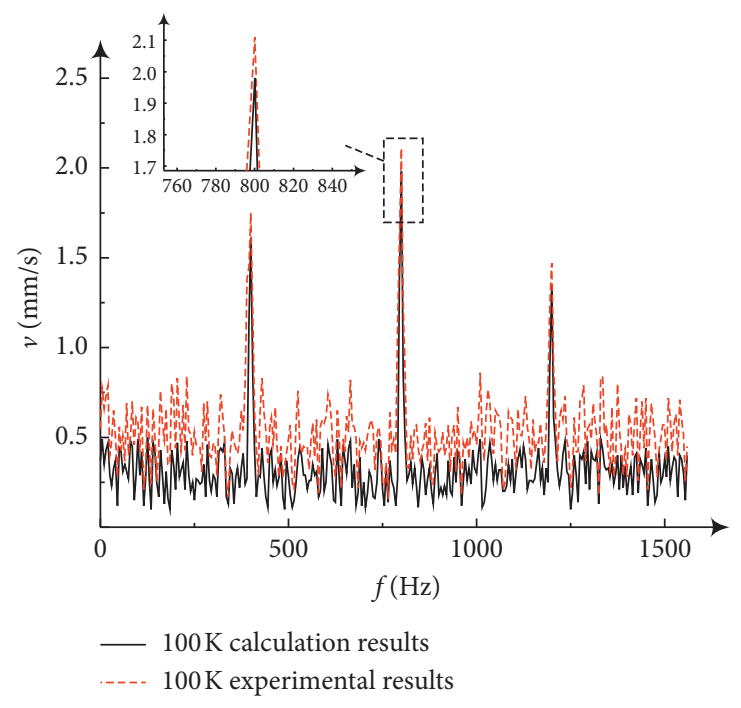

(a)

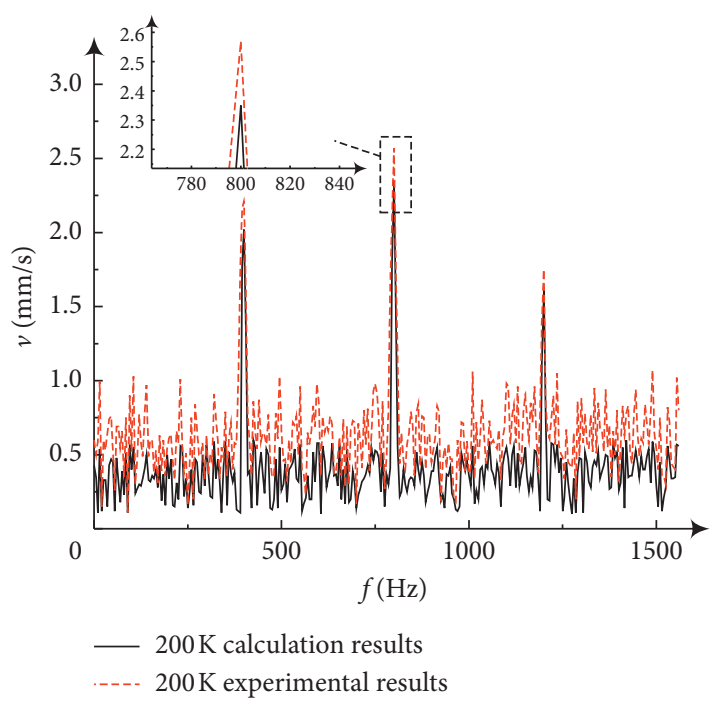

(b)

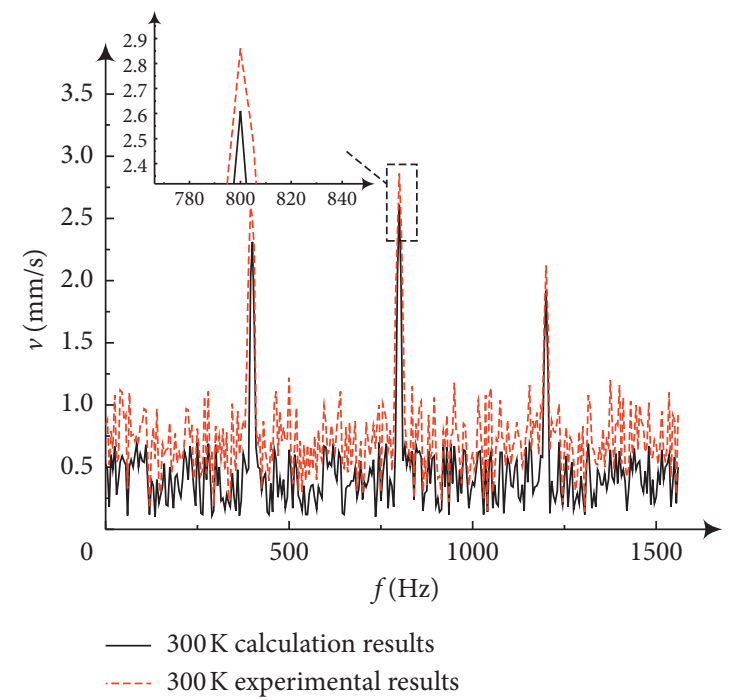

(c)

FIgURE 8: Calculation and experimental results at (a) $100 \mathrm{~K}$, (b) $200 \mathrm{~K}$, and (c) $300 \mathrm{~K}$.

It can be seen from Figure 10 that the amplitudes of the character frequencies increase monotonically with the temperature and the amplitudes of even orders are generally larger than the odd orders. The increase of the amplitudes is slow at $T=100 \mathrm{~K}$ and $200 \mathrm{~K}$ but grows faster at $T=500 \mathrm{~K}$ and $600 \mathrm{~K}$. It is clear that when the range of working temperature exceeds $300 \mathrm{~K}$, the vibration amplitude of the full ceramic ball bearing grows obviously and the rotation accuracy is affected. The vibration is related with the motion of the outer ring and can be evaluated by the relative tracks. The relative tracks show the positions of $O_{\mathrm{o}}$ in coordinate system $\{O ; Y$, $Z\}$, and the relative tracks of $O_{\mathrm{o}}$ in $0.1 \mathrm{~s}$ at $T=100 \mathrm{~K}$ and $200 \mathrm{~K}$ are shown in Figure 11.

As shown in Figure 11, the relative tracks at $T=100 \mathrm{~K}$ and $200 \mathrm{~K}$ are close to circles, indicating that the motion of the outer ring can cover the fit clearance between the outer ring and the pedestal. The impact between the outer ring and the pedestal is not obvious, and the forces acting on the pedestal is mainly frictional and contact forces. The relative tracks at $T=500 \mathrm{~K}$ and $600 \mathrm{~K}$ are shown in Figure 12.

Compared with Figure 11, the relative tracks in Figure 12 are more irregular and disordered. The tracks are not circular, and in the upper half, the displacement in $Z$ direction is small, indicating that the motion of the outer ring does not cover the fit clearance between the outer ring and the pedestal. The vibration amplitude of the outer ring is less than the fit clearance, and the outer ring is out of contact with the pedestal in the upper half. The contact situations change periodically, thus leading to the impact between the outer ring and the pedestal. As a result, the amplitudes of vibration increase with the fit clearance, and the impact of temperature cannot be ignored.

5.2. Analysis on the Dynamic Responses at Different Rotation Speeds. As the full ceramic bearing usually works at high 


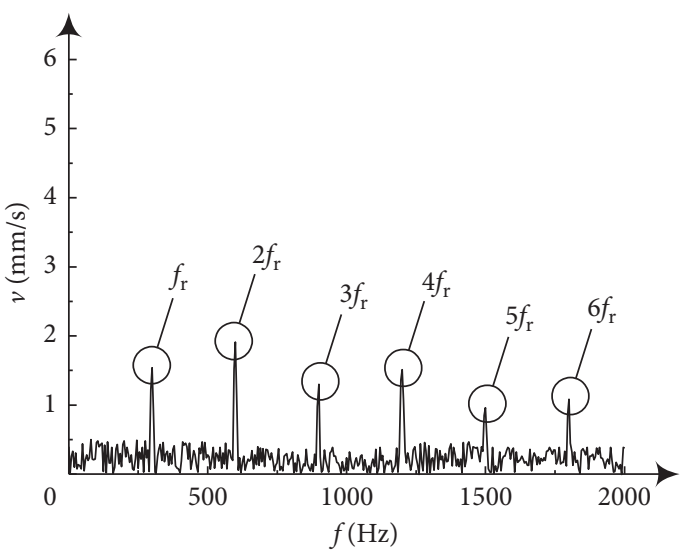

(a)

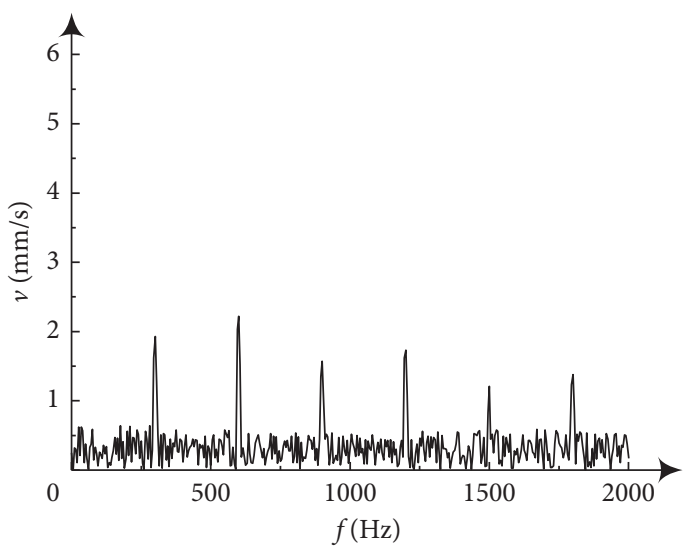

(c)

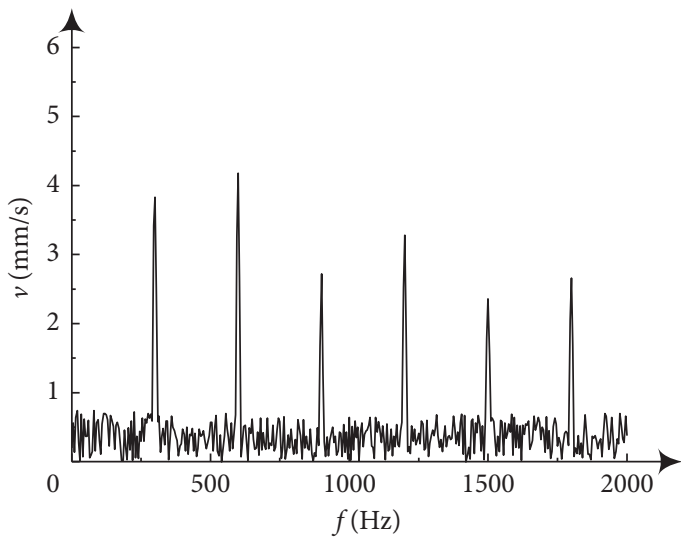

(e)

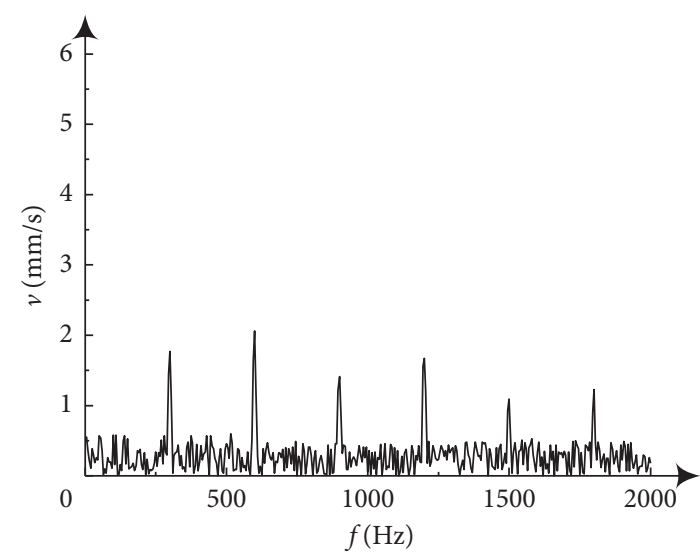

(b)

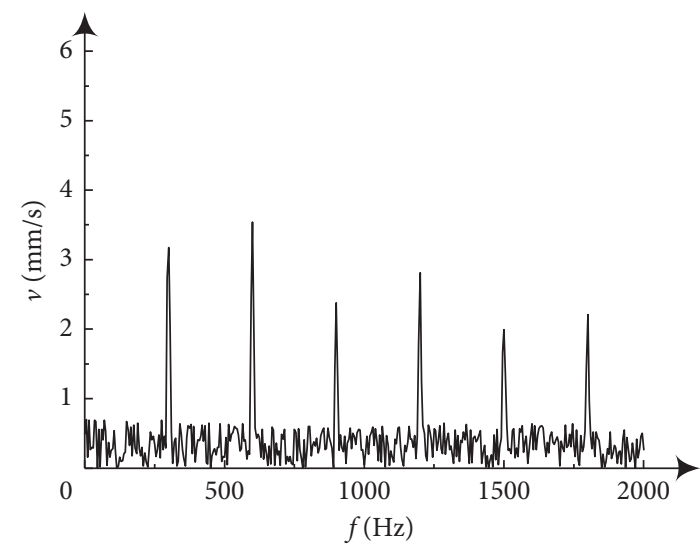

(d)

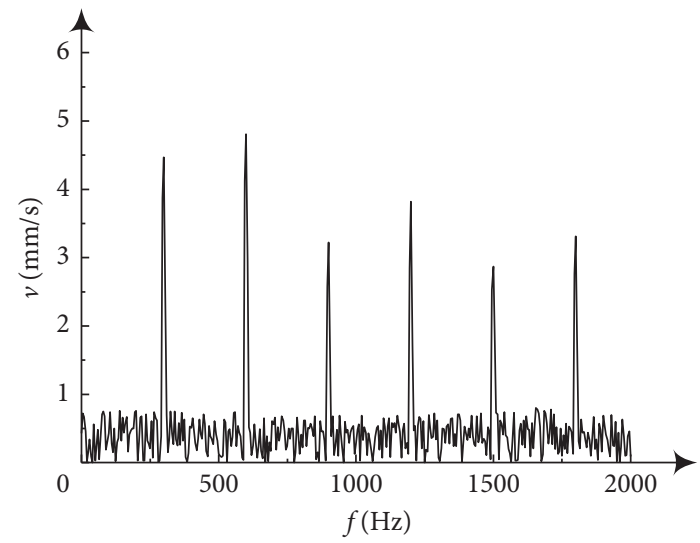

(f)

FIgURE 9: Vibration of the outer ring at (a) $T=100 \mathrm{~K}$, (b) $T=200 \mathrm{~K}$, (c) $T=300 \mathrm{~K}$, (d) $T=400 \mathrm{~K}$, (e) $T=500 \mathrm{~K}$, and (f) $T=600 \mathrm{~K}$.

speed over $10000 \mathrm{rpm}$, the forces acting on the rings and balls are greatly affected by the rotation speed. The change of forces leads to the change of vibration, and therefore, the vibration changes obviously with the rotation speed, as shown in Figure 6. As the fit clearance changes, the impact of the rotation speed also changes and needs to be studied. Here, the rotation speeds are set to vary from $10000 \mathrm{rpm}$ to $40000 \mathrm{rpm}$, and the calculation step is $5000 \mathrm{rpm}$. The axial and radial loads are $1000 \mathrm{~N}$ and $100 \mathrm{~N}$, respectively. The temperatures are set as $T=300 \mathrm{~K}$ and $600 \mathrm{~K}$, and the results of the outer ring vibration are shown in Figure 13.

It can be seen from Figure 13 that the trends of outer ring vibration are different at $T=300 \mathrm{~K}$ and $600 \mathrm{~K}$. When the temperature is $300 \mathrm{~K}$, the change of the vibration amplitudes is not obvious, and the peak values appear at $15000 \mathrm{rpm}$ and $25000 \mathrm{rpm}$. When the temperature comes to $600 \mathrm{~K}$, the vibration amplitudes have an obvious fluctuation from $10000 \mathrm{rpm}$ to $40000 \mathrm{rpm}$, and the peak values appear at 


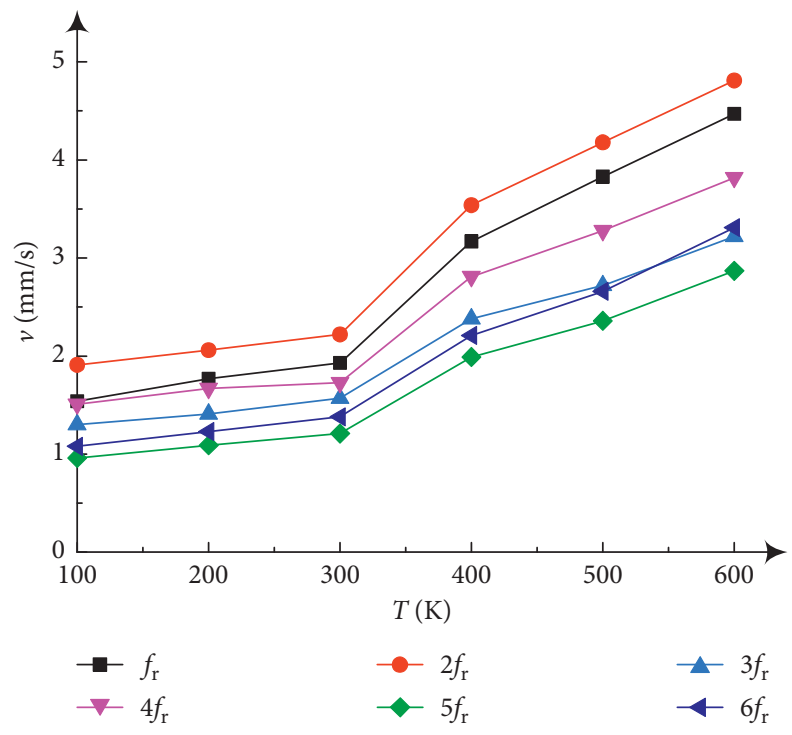

Figure 10: Trends of main frequency components at different temperatures.

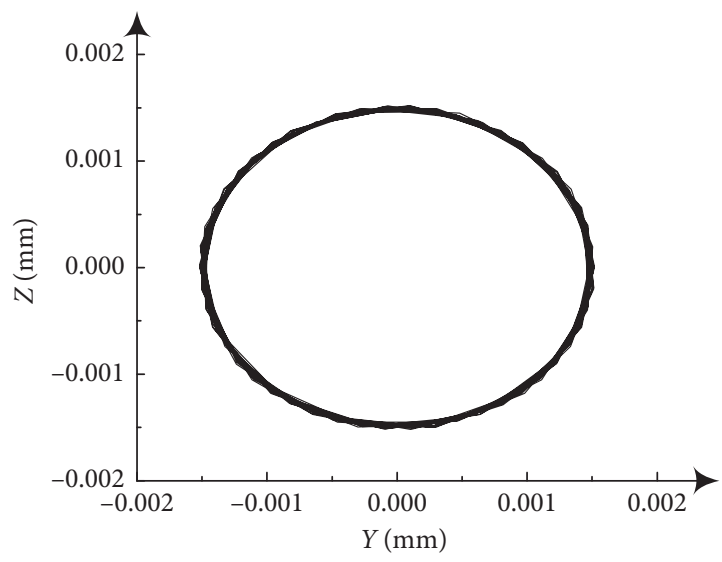

(a)

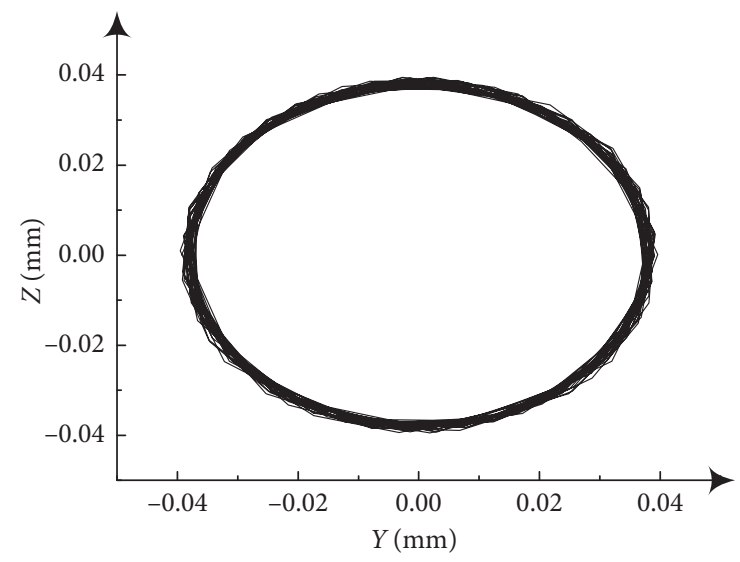

(b)

Figure 11: Relative tracks at (a) $T=100 \mathrm{~K}$ and (b) $T=200 \mathrm{~K}$.

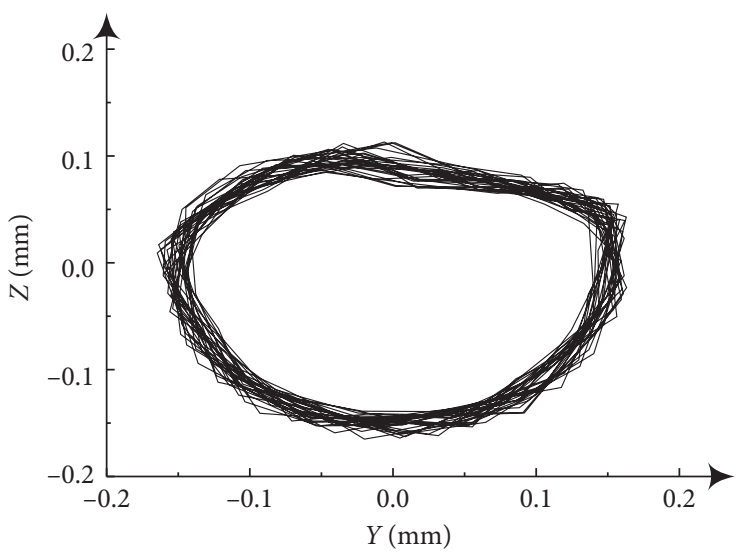

(a)

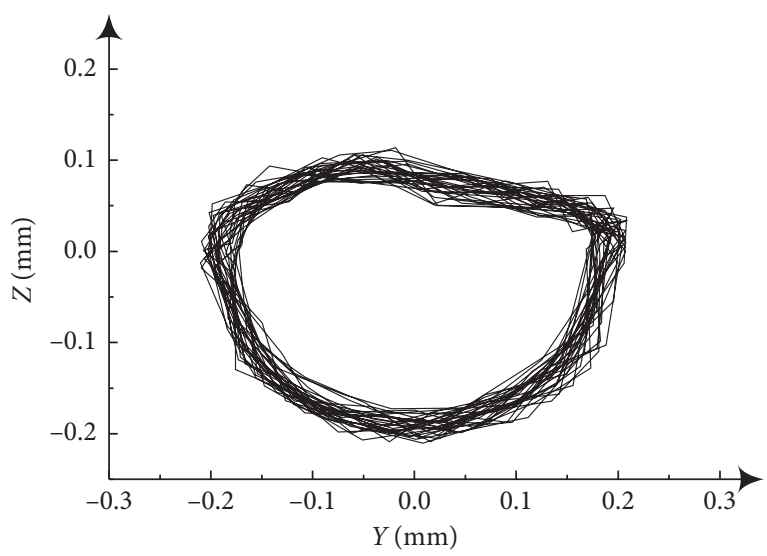

(b)

Figure 12: Relative tracks at (a) $T=500 \mathrm{~K}$ and (b) $T=600 \mathrm{~K}$. 


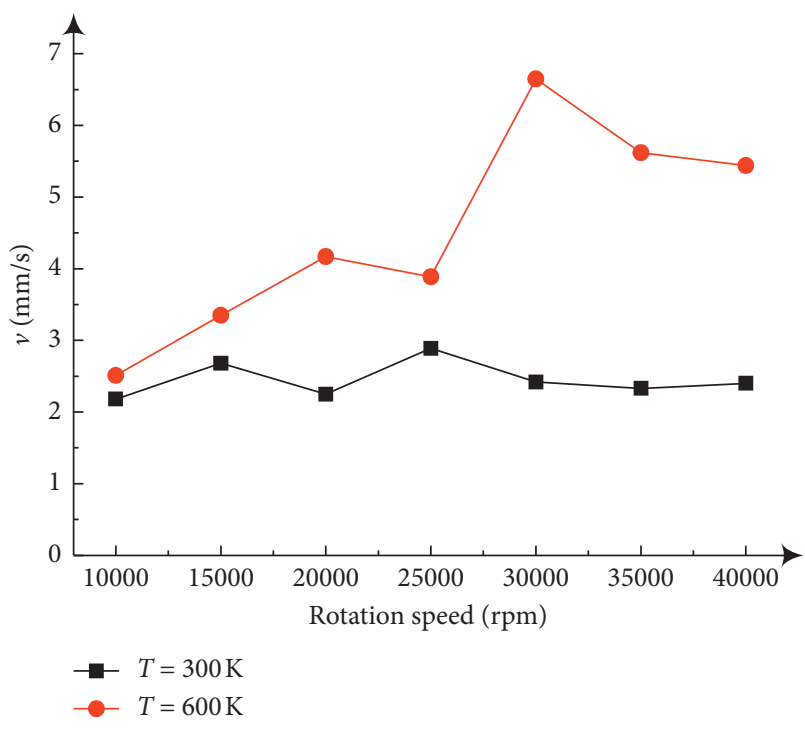

FIgURE 13: Trends of outer ring vibration with rotation speed.

$20000 \mathrm{rpm}$ and $30000 \mathrm{rpm}$. The gap between the maximum value and the minimum value at $T=600 \mathrm{~K}$ is much larger than that at $T=300 \mathrm{~K}$, and the only difference between the two conditions is the fit clearance caused by the thermal deformation. The relative tracks of the outer ring center at $T=300 \mathrm{~K}$ in $0.1 \mathrm{~s}$ are shown in Figure 14.

As shown in Figure 14, the shapes of relative track vary greatly with the increase of rotation speed. At $15000 \mathrm{rpm}$, the amplitude of vibration is small and the motion of the outer ring merely covers about half of the fit clearance between the outer ring and the pedestal. As a result, there exists impact between the outer ring and the pedestal. When the rotation speed increases to $20000 \mathrm{rpm}$, the relative track is close to a circle, indicating that the outer ring has a large vibration amplitude and the outer ring is in contact with the pedestal in the whole circumference. The impact between the outer ring and the pedestal is not obvious, and the vibration amplitude is smaller than that at $15000 \mathrm{rpm}$ accordingly. As the rotation speed continues to rise to $25000 \mathrm{rpm}$, the shape of the relative track is irregular in the upper half and the impact between the outer ring and the pedestal makes contribution to the vibration of the outer ring. The impact has more effect on the vibration, and the amplitude of vibration also rises. When the rotation speed comes to $30000 \mathrm{rpm}$, the motion of the outer ring covers the fit clearance again and the vibration amplitude decreases. It can be inferred that the bearing system comes to the critical speeds at around $20000 \mathrm{rpm}$ and $30000 \mathrm{rpm}$, and the intense vibration leads to the increase of range of motion. The range of motion is large enough to cover the fit clearance, leading to the decrease of vibration amplitudes at the critical speeds, as shown in Figure 13.

When the temperature comes to $600 \mathrm{~K}$, the relative tracks in $0.1 \mathrm{~s}$ are shown in Figure 15.

It can be seen from Figure 15 that at the temperature of $600 \mathrm{~K}$, the relative tracks of the outer ring have different shapes at different rotation speeds. Compared with the results in Figure 14, the tracks have greater amplitudes in
Figure 15. However, none of the tracks at rotation speeds of 15000 to $30000 \mathrm{rpm}$ covers the whole fit clearance between the outer ring and pedestal, thus making the effect of impact more obvious. The trends of track amplitudes reveal the impact of rotation speed without boundary restriction and are relevant with the vibration results in Figure 13. The results indicate that when the fit clearance is large enough, the boundary of the pedestal has less limitation on the motion of the outer ring and the impact between the outer ring and the pedestal has more effect on the vibration.

5.3. Analysis on the Effect of Impact and Friction. According to the dynamic model in Figure 2, the interaction forces between the outer ring and the pedestal are mainly the contact forces and the frictional forces, and the contact and frictional forces lead to the vibration of impact and friction. The former studies have shown that the velocity of the outer ring can be regarded as the evaluation index of the vibration and is affected by the thermal-related fit clearance. In former studies, the friction coefficient between the outer ring and the pedestal is set as $f=0.2$, and the effect of friction can be neglected when $f=0$. Then, the velocities of the outer ring with rotation speeds at different temperatures are studied, and the results with and without the effect of friction are shown in Figure 16.

As shown in Figure 16, the trends of the results with and without the effect of friction are similar and the gaps between the results with and without the effect of friction become smaller with the rise of temperature. It can be inferred that at a low temperature, the fit clearance between the outer ring and the pedestal is relatively small and the outer ring has a small displacement. The outer ring moves along the boundary of the pedestal, and the friction forces make a great contribution to the vibration of the outer ring. When the temperature rises, the fit clearance also increases to bring an increment to the displacement of the outer ring. The displacement of the outer ring is not large enough to keep the outer ring moving along the boundary of the pedestal, and the impact occurs between the outer ring and the pedestal. The effect of impact increases with the rise of temperature and rotation speed, and as a result, the effect of friction becomes less obvious.

\section{Discussion}

As displayed above, the vibration of the bearing system is revealed through the velocity of the outer ring and the relative tracks and is relevant to the temperature and rotation speed. When the thermal deformation difference is considered in the model, the calculation results match well with the experimental results. The impact of the shaft vibration is ignored in the model, and therefore, the amplitudes of the calculation results are slightly smaller than those of the experimental results. It is proved through the experiments that the temperature range leads to the change of fit clearance due to different thermal deformations between the outer ring and the pedestal and then makes impact on the vibration. The fit clearance has a remarkable increase from 


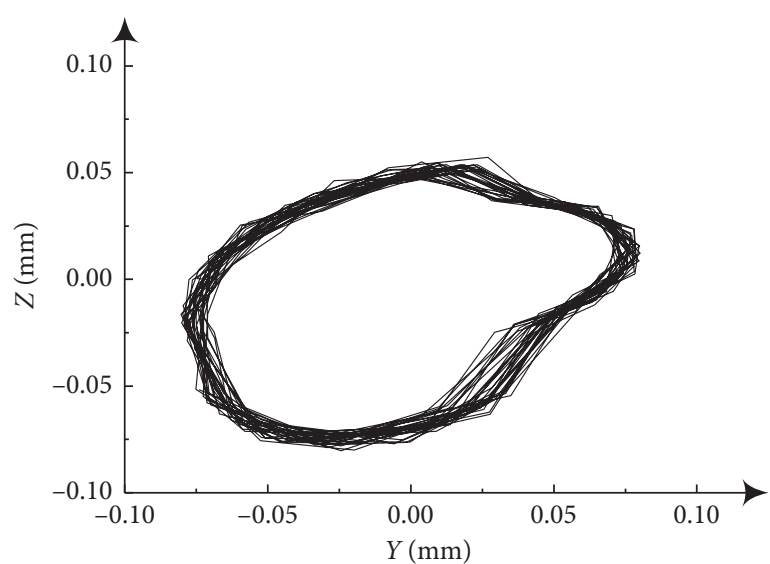

(a)

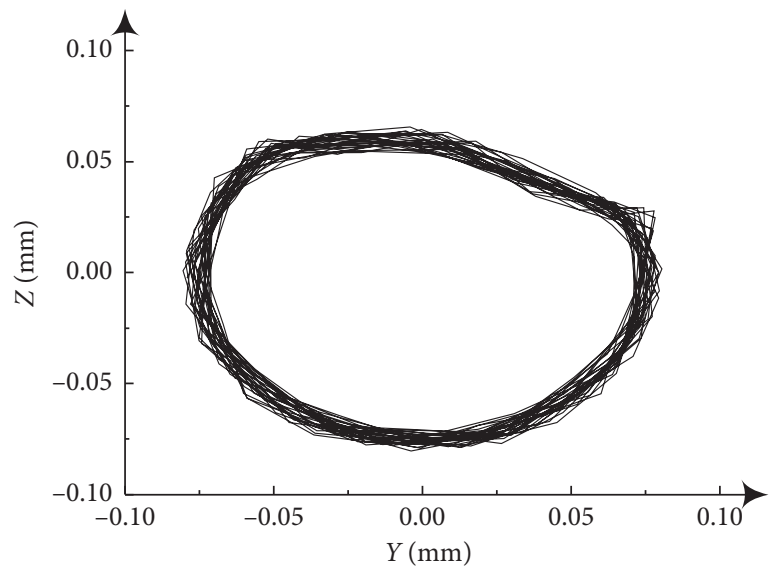

(c)

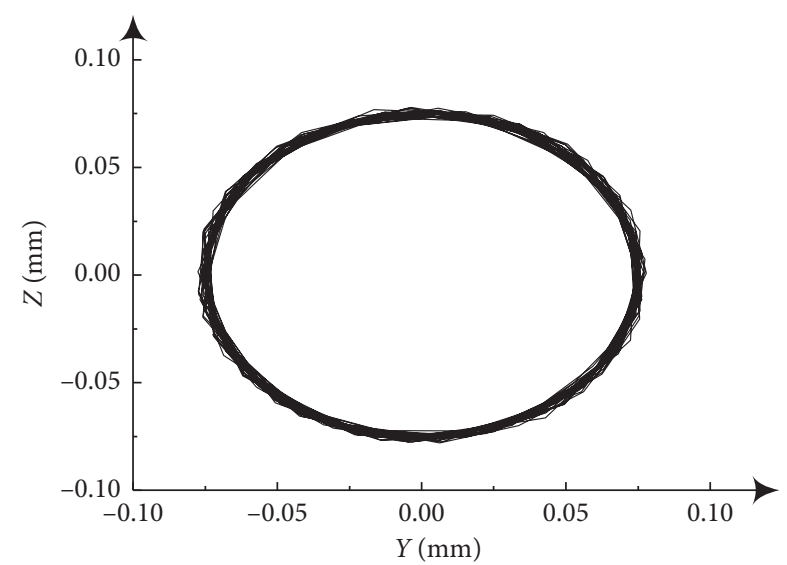

(b)

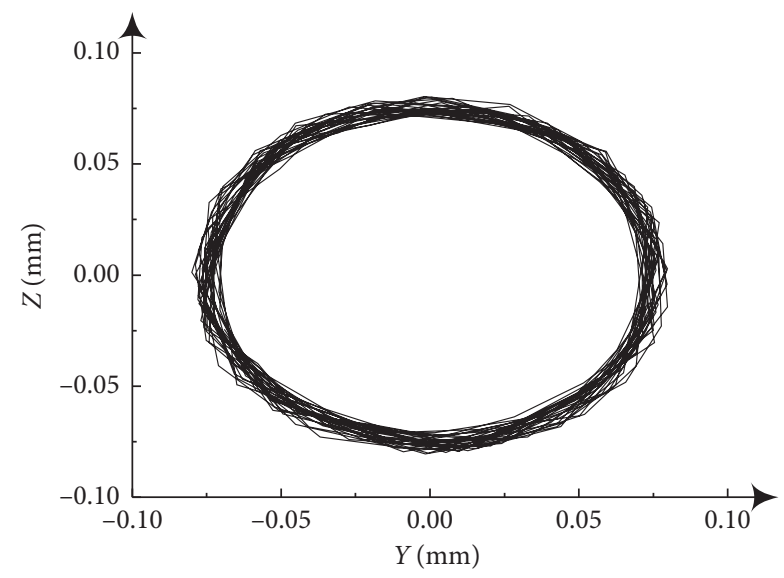

(d)

Figure 14: Relative tracks at $T=300 \mathrm{~K}$ and (a) $15000 \mathrm{rpm}$, (b) $20000 \mathrm{rpm}$, (c) $25000 \mathrm{rpm}$, and (d) $30000 \mathrm{rpm}$.

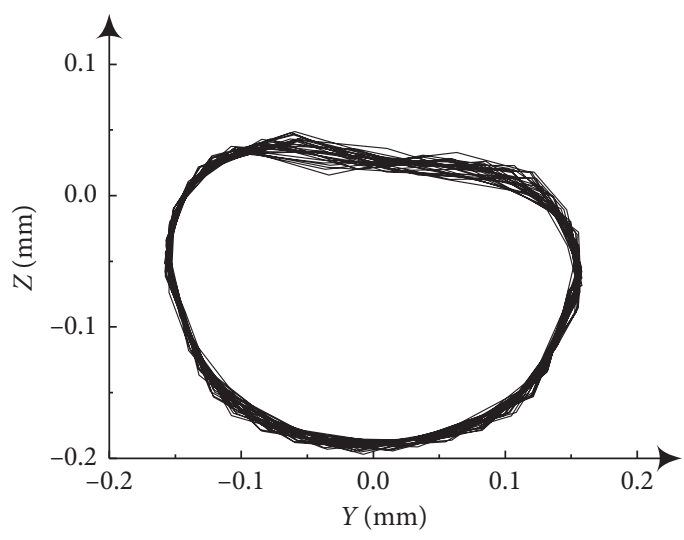

(a)

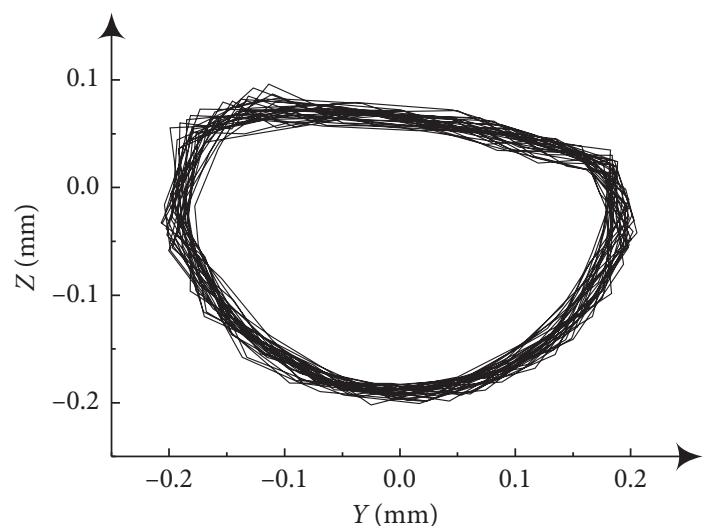

(b)

Figure 15: Continued. 


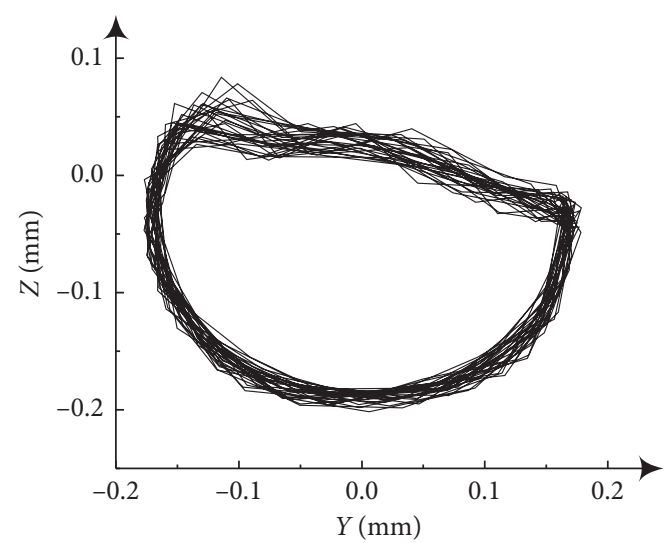

(c)

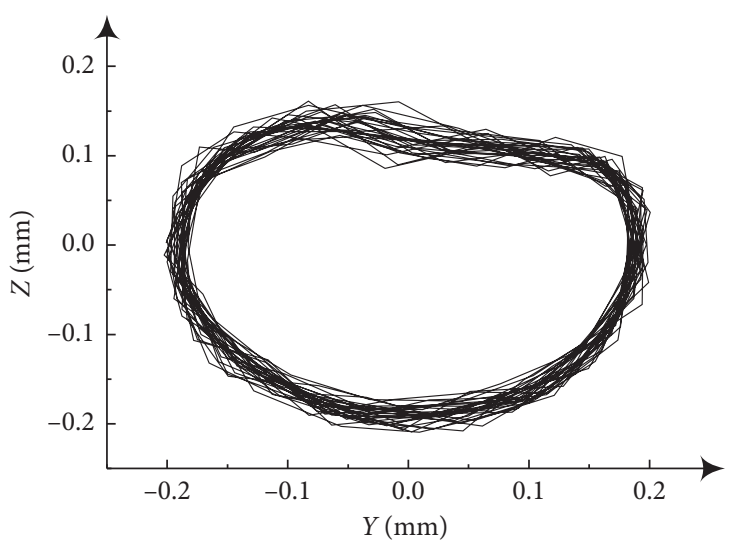

(d)

Figure 15: Relative tracks at $T=600 \mathrm{~K}$ and (a) $15000 \mathrm{rpm}$ (b) $20000 \mathrm{rpm}$, (c) $25000 \mathrm{rpm}$, and (d) $30000 \mathrm{rpm}$.

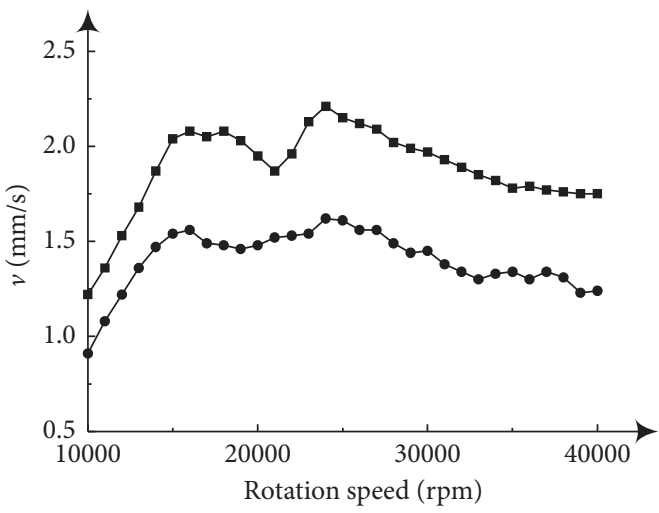

$\rightarrow$ With friction

$\rightarrow$ Without friction

(a)

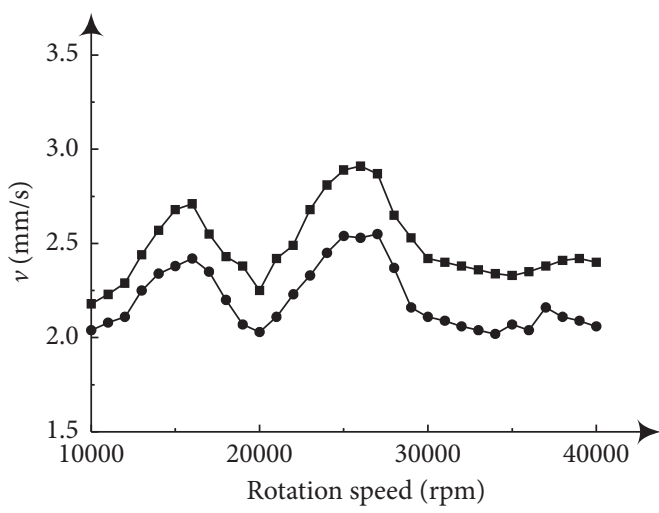

- With friction

$\rightarrow$ Without friction

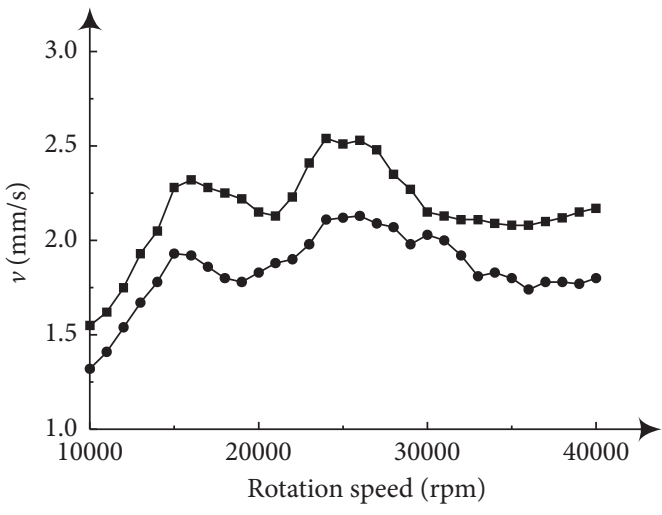

$\rightarrow$ With friction

- Without friction

(b)

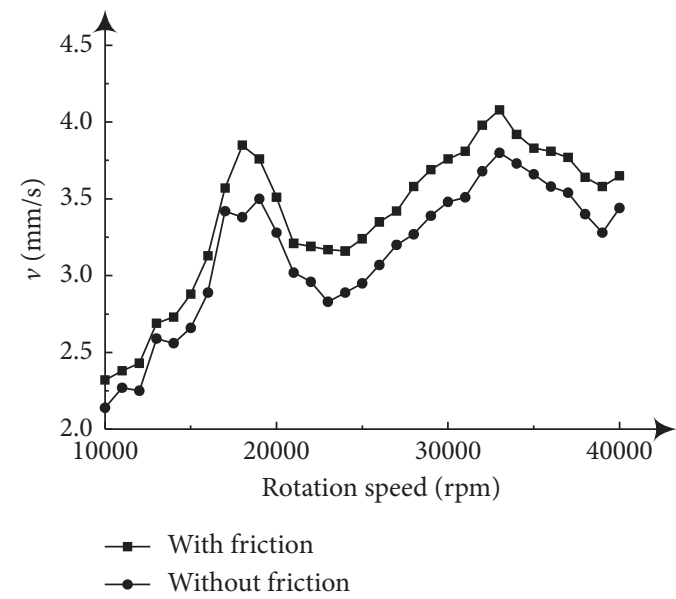

(d)

Figure 16: Continued. 


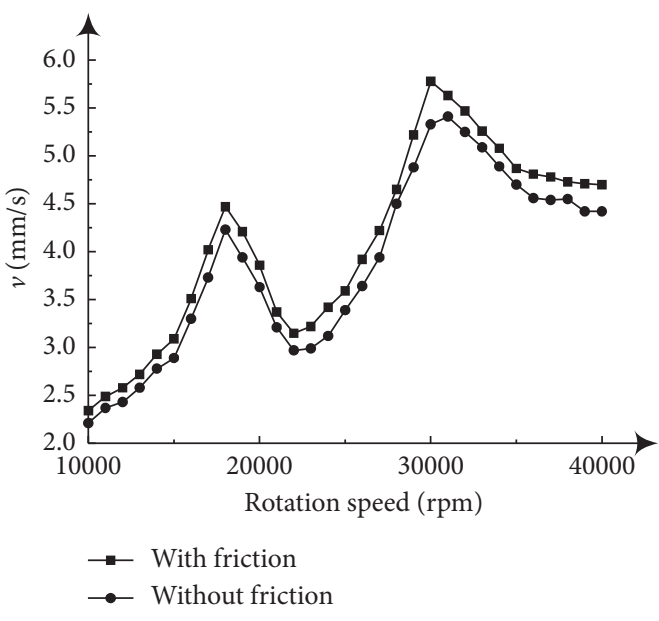

(e)

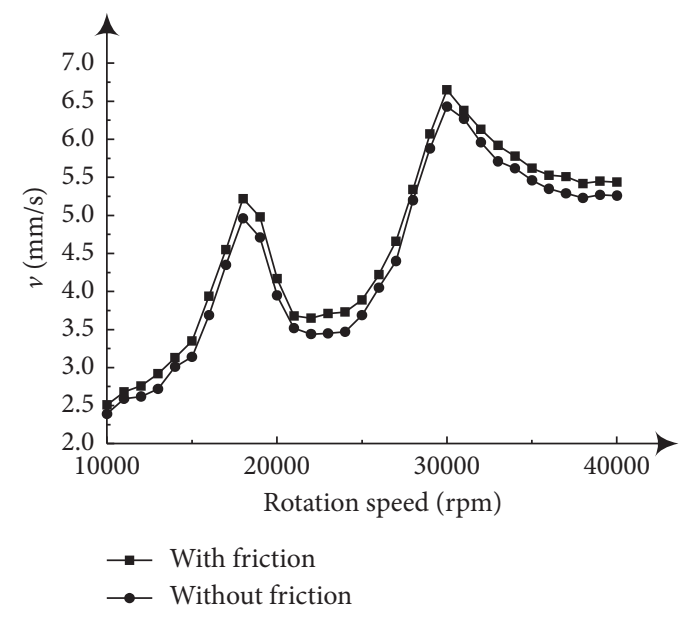

(f)

Figure 16: Results with and without friction at (a) $T=100 \mathrm{~K}$, (b) $T=200 \mathrm{~K}$, (c) $T=300 \mathrm{~K}$, (d) $T=400 \mathrm{~K}$, (e) $T=500 \mathrm{~K}$, and (f) $T=600 \mathrm{~K}$.

$0.003 \mathrm{~mm}$ at $100 \mathrm{~K}$ to over $0.38 \mathrm{~mm}$ at $600 \mathrm{~K}$ and provides a large space for the motion of the outer ring. At low temperatures, the fit clearance is relatively small, and the boundary can be easily reached by the outer ring. Therefore, the friction plays a dominant role in the interaction between the outer ring and the pedestal, and the impact is less obvious. When the amplitude of outer ring vibration is large enough to offset the fit clearance, the inner boundary of the pedestal acts as limitation to the vibration and the vibrations vary little with the rotation speed. When the temperature rises, the boundary for vibration becomes larger and the amplitude of vibration also grows. The amplitude of the outer ring vibration is not large enough to offset the fit clearance at low speed, and the outer ring is not in contact with the pedestal on the whole circumference. The effect of impact starts to occur when the track of outer ring center is not a circle and brings increments to the amplitudes of vibration. As a result, the trends of outer ring vibration are not relevant with the critical speed when the track of the outer ring and the pedestal boundary coincides at critical speeds but separates at other speeds. As the temperature continues to increase and the amplitude of the outer ring vibration is not large enough to offset at critical speeds, the peak values of the outer ring vibration appear at the critical speeds. The effects of both impact and friction make contributions on the vibration of the outer ring, and the relative contributions depend on the fit clearance. The friction has an obvious impact when the outer ring is in contact with the pedestal on the whole circumference, and the effect of impact becomes more dominant when the fit clearance increases and is not fully covered by the motion of the outer ring.

\section{Conclusion}

This study puts forward a dynamic model with the effect of thermal-related fit clearance between the outer ring and the pedestal, and investigations on the influence of temperature and rotation speed are conducted. When the working temperature changes, the great difference in the thermal deformation coefficients between the outer ring and the pedestal leads to the change of fit clearance. Results of the parametric studies show that when the working temperature rises, the fit clearance has a significant increase and the vibration amplitude of the outer ring also grows rapidly. Furthermore, the trends of the outer ring vibration with the rotation speeds also changes at different working temperatures. The change is related with the impact and friction between the outer ring and the pedestal. When the fit clearance is small and can be covered by the motion of the outer ring, the motion of the outer ring is restricted by the pedestal and the friction has an obvious impact on the vibration. When the fit clearance increases and cannot be offset by the outer ring vibration, the outer ring vibration is affected by the critical speeds and the impact becomes the major factor. As a result, the peaks at the critical speeds are more obvious with the rise of the working temperature. According to the vibration results, the thermal-related fit clearance has an obvious impact on the vibration of the full ceramic bearings and the vibration amplitude has large fluctuations with temperature and rotation speed. Therefore, when the rotation accuracy and vibration amplitudes are crucial parameters in the full ceramic bearing system, the working temperature range should be controlled below $300 \mathrm{~K}$ and the critical speeds need to be avoided at high temperatures. The findings provide theoretical foundations for the application of full ceramic bearings and are of great significance for further design.

\section{Data Availability}

The readers can access the data through communication with the authors at acetyws@163.com.

\section{Conflicts of Interest}

The authors declare that there are no conflicts of interest regarding the publication of this paper. 


\section{Acknowledgments}

This work was supported by the National Natural Science Foundations of China (grant numbers 51675353, 51705341, and 51905357), and Doctor Start-up Foundation of Liaoning Province (grant number 20170520147).

\section{References}

[1] S. Xi, H. Cao, and X. Chen, "Dynamic modeling of spindle bearing system and vibration response investigation," $\mathrm{Me}$ chanical Systems and Signal Processing, vol. 114, pp. 486-511, 2019.

[2] P. K. Gupta, "Dynamics of rolling-element bearings-part I: cylindrical roller bearing analysis," Journal of Lubrication Technology, vol. 101, no. 3, pp. 293-304, 1979.

[3] P. K. Gupta, "Dynamics of rolling-element bearings-part II: cylindrical roller bearing results," Journal of Lubrication Technology, vol. 101, no. 3, pp. 305-311, 1979.

[4] P. K. Gupta, "Dynamics of rolling-element bearings-part III: ball bearing analysis," Journal of Lubrication Technology, vol. 101, no. 3, pp. 312-318, 1979.

[5] P. K. Gupta, "Dynamics of rolling-element bearings-part IV: ball bearing analysis," Journal of Lubrication Technology, vol. 101, no. 3, pp. 312-318, 1979.

[6] Y. L. Wang, W. Z. Wang, S. G. Zhang, and Z. Zhao, "Effects of raceway surface roughness in an angular contact ball bearing," Mechanism and Machine Theory, vol. 121, pp. 198-212, 2018.

[7] Y. Wang, W. Wang, and Z. Zhao, "Effect of race conformities in angular contact ball bearing," Tribology International, vol. 104, pp. 109-120, 2016.

[8] X. Li, K. Yu, H. Ma et al., "Analysis of varying contact angles and load distributions in defective angular contact ball bearing," Engineering Failure Analysis, vol. 91, pp. 449-464, 2018.

[9] J. Zhang, B. Fang, J. Hong, and Y. Zhu, "Effect of preload on ball-raceway contact state and fatigue life of angular contact ball bearing," Tribology International, vol. 114, pp. 365-372, 2017.

[10] L. Bizarre, F. Nonato, and K. L. Cavalca, "Formulation of five degrees of freedom ball bearing model accounting for the nonlinear stiffness and damping of elastohydrodynamic point contacts," Mechanism and Machine Theory, vol. 124, pp. 179-196, 2018.

[11] S. Kerst, B. Shyrokau, and E. Holweg, "A semi-analytical bearing model considering outer race flexibility for model based bearing load monitoring," Mechanical Systems and Signal Processing, vol. 104, pp. 384-397, 2018.

[12] Q. Han and F. Chu, "Nonlinear dynamic model for skidding behavior of angular contact ball bearings," Journal of Sound and Vibration, vol. 354, pp. 219-235, 2015.

[13] Q. Han, X. Li, and F. Chu, "Skidding behavior of cylindrical roller bearings under time-variable load conditions," International Journal of Mechanical Sciences, vol. 135, pp. 203-214, 2018.

[14] K. Yan, J. Zhang, J. Hong, Y. Wang, and Y. Zhu, "Structural optimization of lubrication device for high speed angular contact ball bearing based on internal fluid flow analysis," International Journal of Heat and Mass Transfer, vol. 95, pp. 540-550, 2016.

[15] D. Zheng and W. Chen, "Thermal performances on angular contact ball bearing of high-speed spindle considering structural constraints under oil-air lubrication," Tribology International, vol. 109, pp. 593-601, 2017.
[16] W. Zhang, S. Deng, G. Chen, and Y. Cui, "Impact of lubricant traction coefficient on cage's dynamic characteristics in highspeed angular contact ball bearing," Chinese Journal of Aeronautics, vol. 30, no. 2, pp. 827-835, 2017.

[17] B. Choe, J. Lee, D. Jeon, and Y. Lee, "Experimental study on dynamic behavior of ball bearing cage in cryogenic environments, part I: effects of cage guidance and pocket clearances," Mechanical Systems and Signal Processing, vol. 115, pp. 545-569, 2019.

[18] B. Choe, W. Kwak, D. Jeon, and Y. Lee, "Experimental study on dynamic behavior of ball bearing cage in cryogenic environments, part II: effects of cage mass imbalance," Mechanical Systems and Signal Processing, vol. 116, pp. 25-39, 2019.

[19] S. Noguchi, K. Hiruma, H. Kawa, and T. Kanada, "The Influence of location of balls and ball diameter difference in rolling bearings on the nonrepetitive runout (NRRO) of retainer revolution," Precision Engineering, vol. 29, no. 1, pp. 11-18, 2005.

[20] B. Fang, J. Zhang, K. Yan, J. Hong, and M. Yu Wang, "A comprehensive study on the speed-varying stiffness of ball bearing under different load conditions," Mechanism and Machine Theory, vol. 136, pp. 1-13, 2019.

[21] Y. Mao, L. Wang, and C. Zhang, "Influence of ring deformation on the dynamic characteristics of a roller bearing in clearance fit with housing," International Journal of Mechanical Sciences, vol. 138-139, pp. 122-130, 2018.

[22] G. Chen and M. Qu, "Modeling and analysis of fit clearance between rolling bearing outer ring and housing," Journal of Sound and Vibration, vol. 438, pp. 419-440, 2019.

[23] X. Zhou, H. Zhang, X. Hao, X. Liao, and Q. Han, "Investigation on thermal behavior and temperature distribution of bearing inner and outer rings," Tribology International, vol. 130, pp. 289-298, 2019.

[24] N. Neisi, J. E. Heikkinen, and J. Sopanen, "Influence of surface waviness in the heat generation and thermal expansion of the touchdown bearing," European Journal of Mechanics-A/ Solids, vol. 74, pp. 34-47, 2019.

[25] X. T. Bai, Y. H. Wu, I. C. Rosca, K. Zhang, and H. T. Shi, "Investigation on the effects of the ball diameter difference in the sound radiation of full ceramic bearings," Journal of Sound and Vibration, vol. 450, pp. 231-250, 2019.

[26] X. T. Bai, Y. H. Wu, K. Zhang, C. Z. Chen, and H. P. Yan, "Radiation noise of the bearing applied to the ceramic motorized spindle based on the sub-source decomposition method," Journal of Sound and Vibration, vol. 410, pp. 35-48, 2017. 


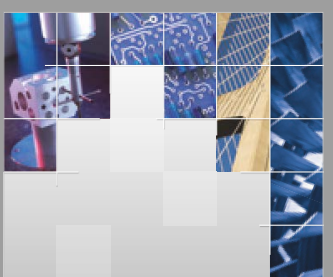

\section{Enfincering}
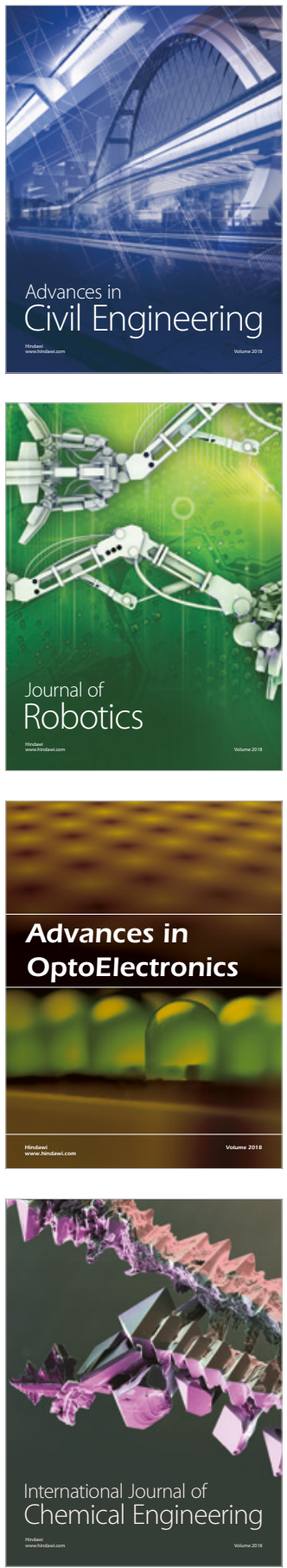

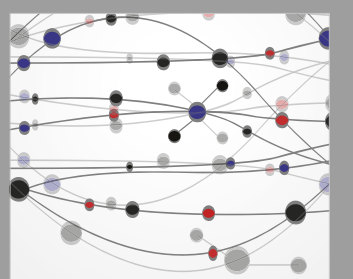

\section{Rotating \\ Machinery}

The Scientific World Journal

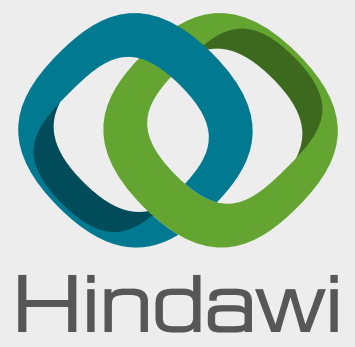

Submit your manuscripts at

www.hindawi.com
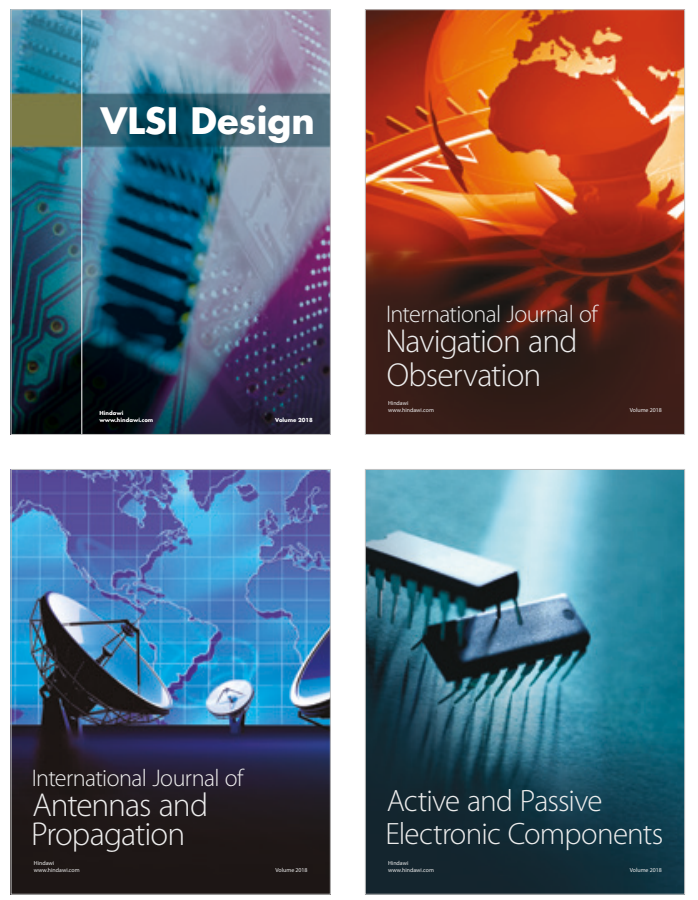
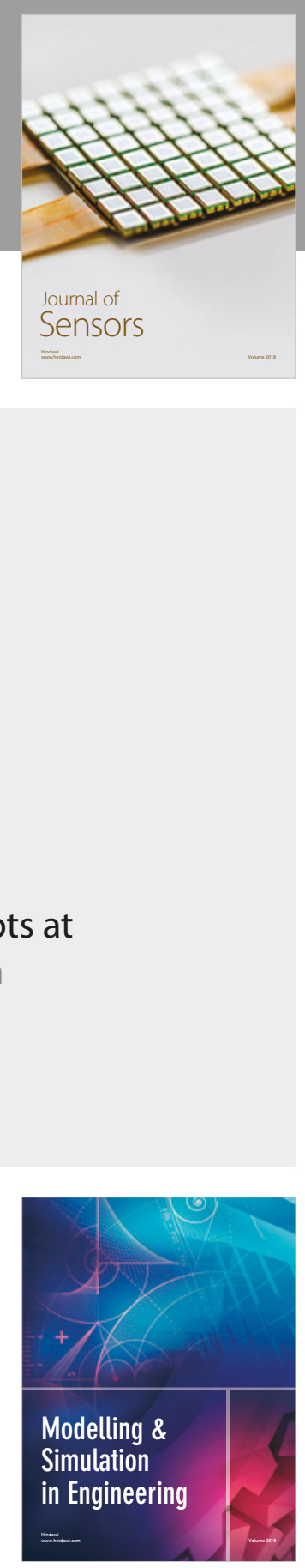

\section{Advances \\ Multimedia}
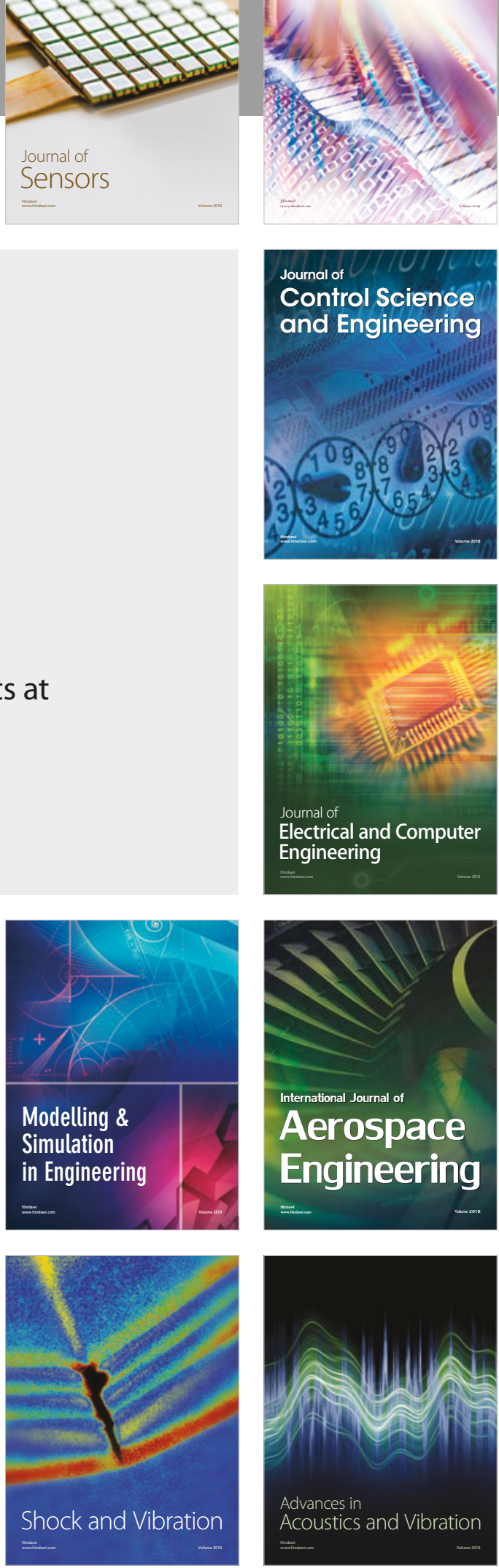